\title{
1 Dysfunctional TRPM8 signalling in the vascular 2 response to environmental cold in ageing.
}

Dibesh Thapa1, João de Sousa Valente ${ }^{1}$, Brentton Barrett ${ }^{1}$, Fulye Argunhan ${ }^{1}$, Sheng Y.

5 Lee $^{1,2}$, Sofya Nikitochkina ${ }^{1}$, Xenia Kodji ${ }^{1,3}$, and Susan D. Brain ${ }^{1 *}$

${ }^{1}$ Section of Vascular Biology and Inflammation, School of Cardiovascular Medicine and Sciences, BHF Centre of Research Excellence, King's College London, Franklin-Wilkins Building, Waterloo Campus, King's College London, London SE1 9NH, UK.

${ }^{2}$ Cancer Research UK, Cambridge Institute, University of Cambridge, Cambridge, CB2 ORE, UK.

${ }^{3}$ Skin Research Institute, Agency of Science, Technology, and Research (A*STAR), 8A Biomedical Grove, \#06-21 Immunos, Singapore 138648.

Corresponding author $\left(^{*}\right)$ :

Professor Susan D. Brain

Vascular Biology and Inflammation Section, School of Cardiovascular Medicine and Sciences,

BHF Cardiovascular Centre of Excellence,

18 King's College London,

Franklin-Wilkins Building, London SE1 9NH, UK

email: sue.brain@kcl.ac.uk 


\section{Abstract}

Ageing is associated with increased vulnerability to environmental cold exposure. Previously, we identified the role of the cold-sensitive transient receptor potential (TRP) A1, M8 receptors as vascular cold sensors in mouse skin. We hypothesised that this dynamic cold-sensor system may become dysfunctional in ageing. We show that behavioural and vascular responses to skin local environmental cooling are impaired with even moderate ageing, with reduced TRPM8 gene/protein expression especially. Pharmacological blockade of the residual TRPA1/TRPM8 component substantially diminished the response in aged, compared with young mice. This implies the reliance of the already reduced cold-induced vascular response in ageing mice on remaining TRP receptor activity. Moreover, sympathetic-induced vasoconstriction was reduced with downregulation of the $\alpha_{2 c}$ adrenoceptor receptor in ageing. The cold-induced vascular response is important for sensing cold and retaining body heat and health. These findings reveal that cold sensors, essential for this neurovascular pathway, decline as ageing onsets.

\section{Introduction}

Upon exposure to cold, depending on the type and intensity, several counterbalancing responses are produced, such as the behavioural response of shivering thermogenesis involving skeletal muscle, or biochemical responses such as non-shivering thermogenesis in brown adipose tissue (BAT) and peripheral vasoconstriction in skin (Señarís et al., 2018, Morrison, Shaun F., Nakamura, 2011, Morrison, S. F., Nakamura, 2019). To produce such responses, thermo-sensors in the form of temperature sensitive sensory receptors are distributed throughout the skin and are considered to work as a first line of defence against cold, which makes peripheral cutaneous responses a fundamental event in the defence against environmental thermal challenge. The sensory receptors in the skin initiate the vascular cold constrictor response which acts to protect against body heat loss and prevent hypothermia. This response is followed by the subsequent vasodilation, a restorative response that is essential to protect the affected skin against cold-induced conditions, such as chilblains, trench foot, frostbite, and Raynaud's condition (Daanen, van der Struijs, Norbert R., 2005, Keatinge, 1957, Lewis, 1930). It is a finely tuned well balanced response that maintains cellular function and physiological homeostasis during cold exposure. Whilst this response is relevant to all ages, physiological changes in ageing leads to dysfunctional signalling which causes a reduced adaptation to cold exposure (Guergova, Dufour, 2011). With the lack of physical activity in the elderly population, it exacerbates the fall in core body temperature which can cause fatal cardiovascular and respiratory problems (Billeter et al., 2014, Stares, Kosatsky, 2015). This is normally the biggest cause behind the NHS excess winter deaths that we witness every year, where in 2018 it caused approximately 11,000 deaths linked to cold exposure in England (Office for National Statistics, 2019).

We have previously delineated the primary roles of transient receptor potential (TRP) channels in producing a distinctive biphasic vascular response to cold in the mouse paw consisting of a TRP ankyrin 1 (TRPA1)/ melastatin 8 (TRPM8)-initiated sympathetic $\alpha_{2 c}$ adrenoceptor mediated neuronal vasoconstriction and a distinct TRPA1-CGRP mediated sensoryvasodilator component (Aubdool et al., 2016). TRPA1 is a biomolecular sensor for noxious cold $\left(<18^{\circ} \mathrm{C}\right)$, mediating aversive behaviour such as avoiding cold-induced pain, whilst also being involved in mediating inflammatory pain (Kwan et al., 2006, Nassini et al., 2014, Jain et al., 2011, Gouin et al., 2017). Additionally, it activates $C$ and Aঠ் sensory nerves to release neuropeptides such as CGRP to mediate neurogenic vasodilation (Aubdool et al., 2016, Story et al., 2003, Gentry et al., 2010). TRPM8 is sensitive to cool temperatures $\left(<28^{\circ} \mathrm{C}\right)$ (McKemy, Neuhausser \& Julius, 2002, Peier et al., 2002). It is involved in deep body cooling and suggested to supersede the role of TRPA1 (Gavva et al., 2012). TRPM8 is also suggested to 
be a vasoactive stimulus (Bautista et al., 2007, Johnson et al., 2005, Silva et al., 2019). The other established receptor that plays a pivotal role in cold signalling is the sympathetic $\alpha_{2 c}$ adrenoceptor, which mediates the vasoconstriction of the blood vessels (Bailey et al., 2004). Whilst the sympathetic branch that is involved in the vasoconstrictor component of the cold response has been shown to have reduced activity in ageing humans (Holowatz, ThompsonTorgerson \& Kenney, 2010, Degroot, Kenney, 2007), little is known about the functionality of the cold receptors TRPA1 and TRPM8 in ageing. In the current study we hypothesize that signalling via the cold receptors TRPA1 and TRPM8 deteriorates with ageing which causes an impaired vascular response to the cold.

The primary objective of this study is to investigate the cutaneous vascular response to cold in ageing, focusing on the activity of cold TRP receptors; TRPA1 and TRPM8. As sympatheticsensory neuronal signalling is key for the cutaneous vascular cold response in ageing, we also searched for evidence of dysfunction within these systems. Here using in vivo, ex vivo, genetic, and pharmacological approaches we show that TRPA1 and TRPM8 signalling declines with ageing which affects the sensing as well as functional pathways involved in cold signalling; all of which contribute to the impaired cold vascular response. Additionally, we provide evidence that the $\alpha_{2 c}$ adrenoceptor as well as the TRPM8 receptor both play critical roles to influence this outcome, as the expression of both diminishes significantly in ageing which impacts the vascular response to cold. These important findings establish the dynamic role of cold sensitive TRP receptors and sympathetic receptors in the cutaneous vascular response to the cold as ageing occurs.

\section{Results}

Cold-induced vascular response is impaired in ageing. We analysed the cold induced vascular response in WT CD1 females (Young: 2-3 months, Aged: 13-15 months) with full-field laser speckle imager (FLPI) using the cold water immersion model (Fig 1a) developed in our laboratory (Aubdool et al., 2014, Pan et al., 2018). After the baseline blood flow was measured for $5 \mathrm{~min}$, the ipsilateral hindpaw was immersed in cold water at $4^{\circ} \mathrm{C}$, a temperature that produces a robust vascular response, for $5 \mathrm{~min}$ and blood flow was then recorded for another $30 \mathrm{~min}$. The cold treatment produced a typical vascular response of rapid vasoconstriction followed by a prolonged recovery vasodilator response in both young and aged mice (Fig 1bc, Supplementary Fig 1a). In young mice, the cold treatment produced a maximum vasoconstriction of $51.1 \pm 1.176 \%$, however, in aged mice this was significantly blunted with maximum vasoconstriction of $27.7 \pm 2.976 \%$ (Fig 1d). These changes were reflected in the area under the response curve (AUC) analysis with a significantly greater response in young than aged mice (Fig 1e). The result was extended by measurement of the blood flow recovery after the cold treatment. Although blood flow did not fully recover back to the baseline, the initial rate of recovery immediately after maximum vasoconstriction before it slowly plateaued off was significantly faster in the young mice compared to the aged mice (Fig 1f). These results suggest that with ageing the cold induced vascular response starts to diminish, which affects both parts of the vascular response. We were surprized that these changes were observed with moderately aged mice, equivalent to middle aged in human terms (Dutta, Sengupta, 2016). However, at this age there is a clear evidence of elevated gene expression in DRG and skin of senescence markers associated with ageing, p16 and p21, (Fig 1g-h) also confirmed by western blotting (Fig 1i).

To extend our mechanistic understanding, we also used a laser Doppler imager (VMS-LDF), in addition to FLPI, which simultaneously measures the blood flow, skin temperature and tissue oxygen saturation level at a single point, to investigate the vascular response to cold. Similar to the results obtained using the FLPI, the environmental cold water treatment produced an impaired vascular response in the paws of aged mice compared to the young 
mice (Fig 2a). In young mice, the cold treatment produced a maximum vasoconstriction of $45.5 \pm 2.952 \%$, however in aged mice this was significantly lower with a maximum vasoconstriction of $23.4 \pm 4.678 \%$, a result which was reflected in AUC analysis (Fig $2 b-c$ ). There was a trend of greater reduction in skin temperature of aged mice after the cold water treatment; however, the aged mice had a significantly higher skin temperature at baseline, suggesting they were losing more body heat and consistent with the fact that the ability to maintain core body temperature declines with ageing (Fig $2 \mathrm{~d}-\mathrm{f}$ ). The tissue oxygen saturation level underwent a similar reduction in both young and aged mice after the cold exposure (Fig $2 \mathrm{~g}-\mathrm{h}$ ) but recovered more robustly in the young mice compared to the aged mice as shown by AUC analysis (Fig 2i). We also found evidence of increased cellular stress as protein expression of 3-nitrotyrosine, a biomarker of oxidative stress produced via reactive nitrogen species was elevated in aged hindpaw skin (Supplementary Fig 2), in keeping with physiological ageing. These results from two distinct techniques confirm our finding that the cold induced vascular response starts to diminish with ageing.

Cold sensitivity is impaired in ageing. To learn if cold sensitivity had altered with ageing, we examined the functionality of TRPA 1 and TRPM 8 channels in behavioural studies using a cold plate set at $4^{\circ} \mathrm{C}, 10^{\circ} \mathrm{C}$, and $20^{\circ} \mathrm{C}$, within the activation range of TRPA1 and TRPM8 receptors (Dhaka et al., 2007, Kwan et al., 2006). At all three cool/cold temperatures, the aged mice showed a significant delayed latency for paw licking/paw withdrawal/jumping compared to the young mice, suggesting impaired cold sensing in aged mice (Fig 3a-c), but with little difference in the total number of responses observed among groups (Fig $d-f)$. When the test was performed at $30^{\circ} \mathrm{C}$, a temperature outside the activation range of TRPA 1 and TRPM8, we observed no delayed latency in response time, although the total number of responses was significantly lower in the aged mice (Fig $3 g-h)$. These results indicate that there is a reduction in sensitivity to cold with ageing at temperatures at which the cold sensors TRPA1 and TRPM8 are active; thus leading us to hypothesise that at least one cold-sensitive TRP pathway deteriorates with ageing. Of note, the largest difference in response time between young and aged mice was observed at $20^{\circ} \mathrm{C}$, in keeping with the TRPM 8 activation range (Fig $3 i$ ).

The cold-induced vascular response remains dependent on TRPA1 but not TRPM8 in ageing. To investigate the role of TRPA1 and TRPM8 in the local cold water immersion test; we measured the cold-induced vascular response in the presence of the TRPA1 antagonist A967079 (100 mg kg-1 i.p.) and TRPM8 antagonist AMTB (10 $\mathrm{mg} \mathrm{kg}^{-1}$ i.p.), a combination previously shown by us to inhibit the cold induced vascular response (Pan et al., 2018). The combined pre-treatment of A967079 and AMTB partially but significantly inhibited the vasoconstriction in young mice. By comparison, this treatment regime produced a more substantial inhibition of vascular responses induced by cold in the aged mice (Fig 4a, 4d). This result reveals that the role of TRP receptors in the cold-induced vascular response remains and suggests as ageing occurs the TRP-mediated signalling may become more important. Next, we performed the cold water immersion test in the presence of either A967079 or AMTB. The A967079 treatment produced a similar effect to the combined antagonist treatment of A967079+AMTB, where the antagonist was more effective in aged than in the young mice (Fig $4 \mathrm{~b}$, Fig 4e). By comparison, the AMTB treatment inhibited the response in young mice, but had no significant effect in the vascular response to cold (Fig 4c, 4f) in aged mice. This provides further evidence that as ageing occurs, TRPM8 loses its ability to respond to local cold treatment. Next, we examined the expression of TRPA1 and TRPM8 in DRGs of young and aged mice. RT-PCR analysis of DRG showed similar level of TRPA1 mRNA in both young and aged mice (Fig $4 \mathrm{~g}$ ). However, the level of TRPM8 mRNA was significantly reduced in the aged compared to the young mice (Fig $4 \mathrm{~h}$ ), as was its protein expression when analysed by western blot (Fig 4i). 
bioRxiv preprint doi: https://doi.org/10.1101/2021.05.10.443379; this version posted May 10, 2021. The copyright holder for this preprint (which was not certified by peer review) is the author/funder. All rights reserved. No reuse allowed without permission.

TRPA1 and TRPM8 vasodilator signalling is impaired in ageing. Thus far we had gained multiple evidence that TRPM8 activity is impaired in vascular signalling in ageing, with some evidence for a reduction in TRPA1 activity. To build on these findings, we examined the vasoactive effect of TRPA1 and TRPM8 agonists that are commonly associated with sensory nerves. The topical application of cinnamaldehyde (CA) and menthol on mouse skin have previously been shown to mediate vasodilation via TRPA1 and TRPM8 channels respectively (Craighead et al., 2017, Aubdool et al., 2016). The topical application of menthol (10\%) to the ear caused increased blood flow in young mice, which was significantly lower in the aged mice (Fig 5a), as shown by the maximum increase in blood flow (Fig 5b). The AUC analysis of blood flow showed significant increase with menthol treatment compared to vehicle in young mice but not in aged mice (Fig 5c). Similarly, cinnamaldehyde (CA, 10\%) application also increased blood flow in young mice, however, this increase was significantly lower in aged mice (Fig $5 d-$ e, Supplementary Fig 3a-b). The AUC analysis showed a significant increase in blood flow with CA treatment compared to vehicle in young mice but not in aged mice (Fig 5f). These findings suggest that the TRPA 1 and TRPM8-mediated vasoactive activity starts to deteriorate in moderate ageing, and it is not exclusive to cold signalling. To build on this concept, we examined whether the activity of another prominent TRP receptor, TRPV1, is also impaired with ageing. To probe this, we studied capsaicin-induced increase in ear blood flow (Grant et al., 2005). The topical application of $10 \%$ capsaicin produced a similar increase in ear blood flow in both young and aged mice (Fig $5 \mathrm{~g}-\mathrm{i}$ ) indicating, unlike the TRPA1 and TRPM8 signalling, the TRPV1 signalling does not deteriorate with ageing.

Dysfunction in sympathetic signalling contributes to impaired cold response in ageing. In comparison to the sensory system, the importance of sympathetic nerves in mediating the vascular smooth muscle constriction in the cold response is well established (Bailey et al., 2004, Smith et al., 2004). To understand whether there is modulation of this pathway as ageing progresses, we examined the sympathetic-mediated vasoconstriction. The response to the intraplantar injection of the non-selective and endogenous sympathetic neurotransmitter noradrenaline (NA) revealed a significantly greater reduction of blood flow in young mice compared to aged mice (Fig 6a-b). Knowing that the $\alpha_{2 c}$ adrenoceptor is essential for cold induced vasoconstriction (Aubdool et al., 2014, Bailey et al., 2004, Honda et al., 2007), we then proceeded to investigate the effect of the selective $\alpha_{2}$ adrenoceptor agonist medetomidine, in hindpaw blood flow. Medetomidine caused immediate vasoconstriction as expected, but the response was blunted in aged mice compared to young mice (Fig 6c-d). These results recapitulate previous findings that suggest a defect also in sympathetic signalling in aged mice involving the $\alpha_{2 c}$ adrenoceptor, in addition to the cold TRP receptors. The western blotting analysis of the hind paw skin showed a significant reduction in the expression of $\alpha_{2 c}$ adrenoceptor in aged mice (Fig 6e). To elucidate further potential defects in the sympathetic pathway with ageing, we investigated the biosynthesis pathway of NA, the major signalling molecule of sympathetic system. Tyrosine hydroxylase (TH), an enzyme that catalyses the rate limiting stage of noradrenaline synthesis, showed a similar level of expression (Fig 6f) including of its active form, phosphorylated $\mathrm{TH}$ in both young and aged mice (Supplementary Fig 4), suggesting the production of noradrenaline remained unaltered with ageing. This indicates that in ageing the expression and function of the $\alpha_{2 c}$ adrenoceptor diminishes and that contributes to the impaired constrictor response against cold.

Sympathetic-sensory signalling and influence of ageing. We extended our investigation of sympathetic system in vascular cold response by exploring potential crosstalk between sympathetic and sensory signalling in ageing. To elucidate this, we first investigated DRG and found that $\alpha_{2 a}$ and $\alpha_{2 c}$ adrenoceptor gene expression was reduced in ageing (Supplementary Fig 5a-b) similar to that shown for the TRPM8 gene, (Fig 4h) whilst no significant difference 
was found for TRPV1 receptors (Supplementary Fig 5c) in keeping with results for TRPA1 (Fig $4 \mathrm{~g}$ ). By comparison, whilst the TRP receptors are well known to be expressed in sensory neurons there is evidence for a broader localisation (Hirai et al., 2018, Jain et al., 2011, Smith et al., 2004, Yang et al., 2006). We investigated the possible expression of these receptors on sympathetic nerves by collecting the sympathetic ganglia from the cervical and thoracic paravertebral regions where they could directly influence the NA transmission that mediates the vasoconstrictor component of the vascular cold response. To confirm the phenotype of sympathetic neurons, we used positive markers such as tyrosine hydroxylase (TH) and dopamine $\beta$-hydroxylase (Supplementary Fig 6 ) both of which exhibited high expression compared to sensory neuron of DRGs and kidney which were used as negative controls. The RT-PCR data on sympathetic ganglia showed the gene expression of both TRPA1 and TRPM8 in young and aged mice. Interestingly, the expression of both receptors were significantly downregulated in aged mice (Fig 7a-b). Whilst there is no feasible selective TRPA1 antibody available, western blot analysis of TRPM8 on sympathetic ganglia recapitulated the qPCR finding of diminished expression in aged mice compared to young mice (Fig 7c). These findings reveal expression of cold TRP receptors in sympathetic neurons which are diminished in ageing. 
$280^{1}$

281

282

283

284

285

286

287

288

289

290

291

292

293

294

295

296

297

298

299

300

301

302 b

Tail Right hind

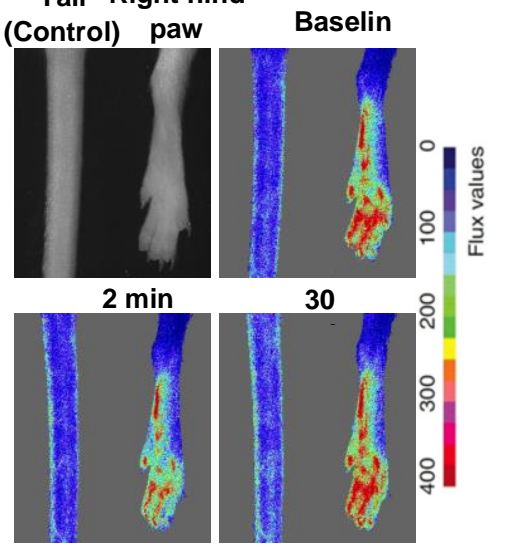

e

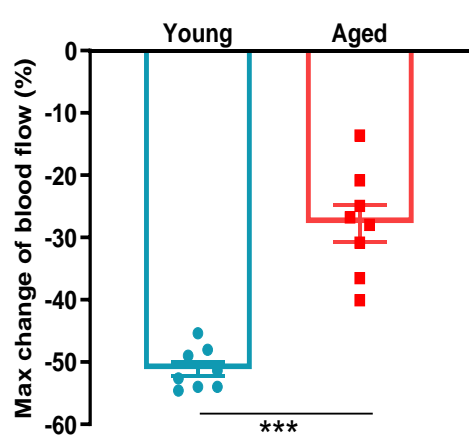

g

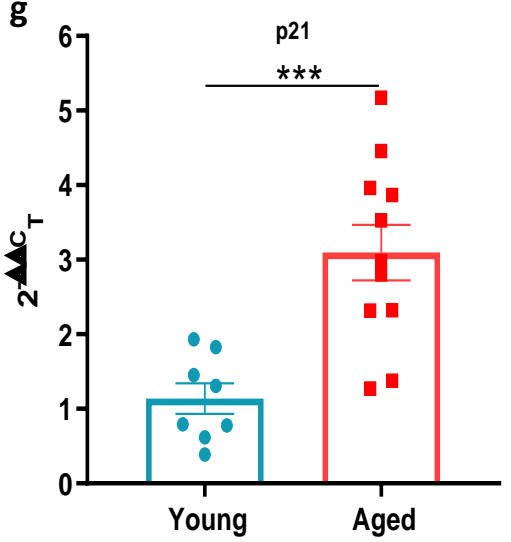

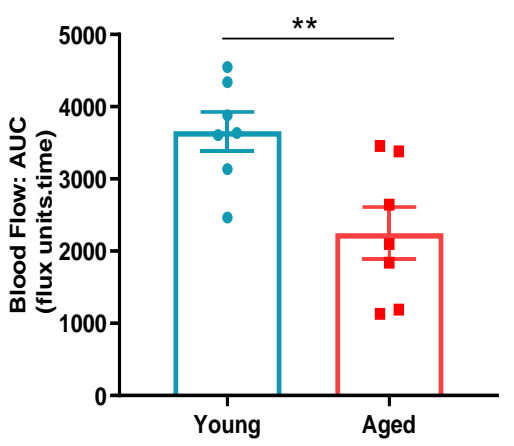

h

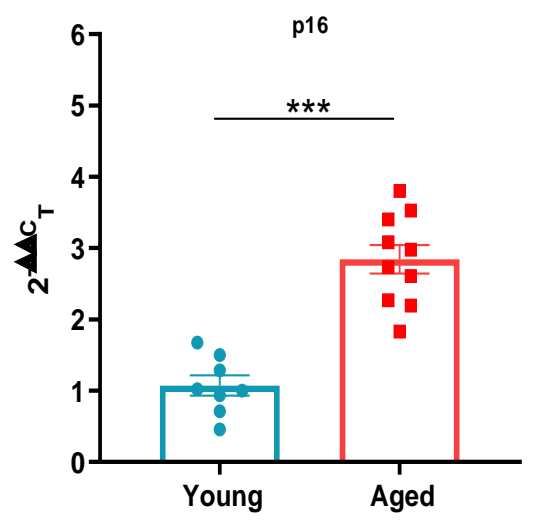

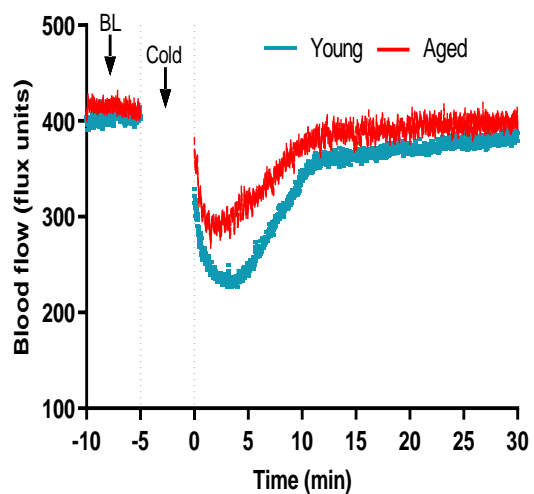

f
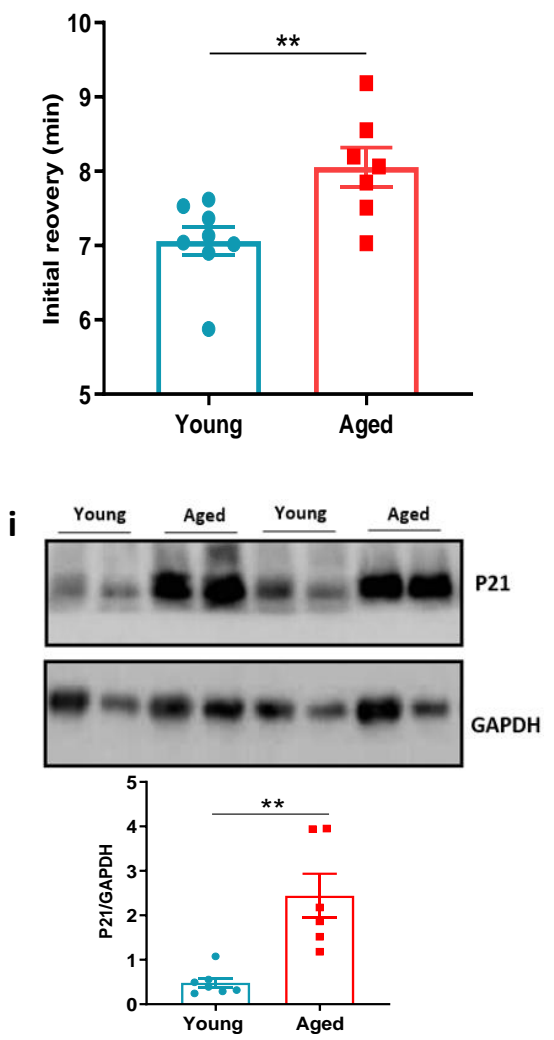

Figure 1: Cold-induced vascular response is impaired with ageing. (a) Diagram illustrates the experimental setup of cold-induced vascular response protocol; FLPI from top measures the blood flow in the hindpaw of the anaesthetized mouse when on a heating mat in response to cold water immersion. The expanded component (highlighted by dotted red lines) shows the hindpaw region in which the blood flow is recorded, and a graph of typical blood flow response is shown. Recording is paused for cold treatment where one of the hindpaw is immersed in cold water for 5 min. (b) Representative FLPI image shows the blood flow in cold-treated hind paw at baseline, 2 min and $30 \mathrm{~min}$ after the cold water treatment. (c) Graph shows the raw blood flow trace (mean) of vascular response with cold $\left(4^{\circ} \mathrm{C}\right)$ water treatment $(n=8)$. (d) \% change in hindpaw blood flow from baseline to $0-2 \mathrm{~min}$ following cold water treatment (maximum vasoconstriction). (e) The AUC to maximum vasoconstriction point assessed by area under the curve (AUC). (f) Time of blood flow recovery immediately after maximum vasoconstriction until the start of the plateau period. (g-h) RT-PCR CT analysis shows fold change of p21 and p16 gene expression normalized to three housekeeping genes in dorsal root ganglia (DRG) of young and aged mice. (i) Representative western blot of p21 in hindpaw skin of young and aged mice and densitometric analysis normalized to GAPDH. (BL = baseline). Data is presented as mean and all error bars indicate s.e.m. ${ }^{* *} p<0.01$, ${ }^{* * *} p<0.001$. (Two-tailed Student's t-test). 
319 a

320

321

322

323

324

326

327

328

329

330

331

332

333

334

335

336

337

338

339

340

341

342

343

344

345

346

347

348

349

350

351

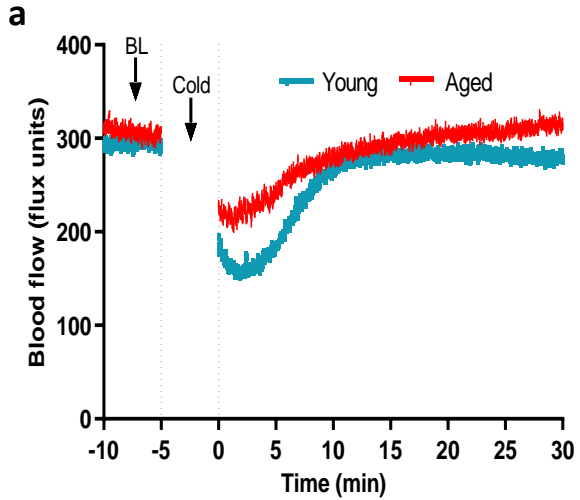

d

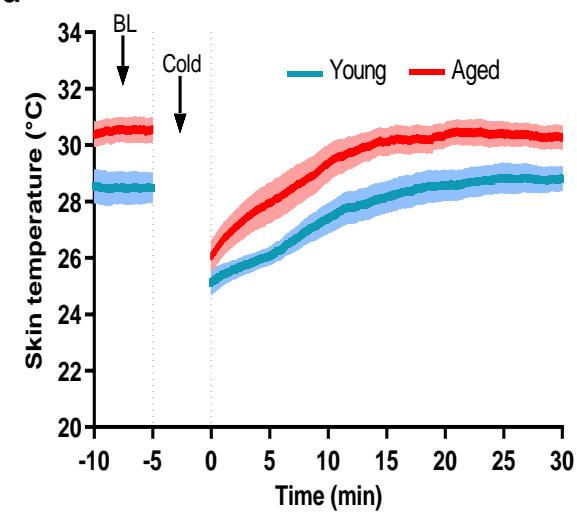

g

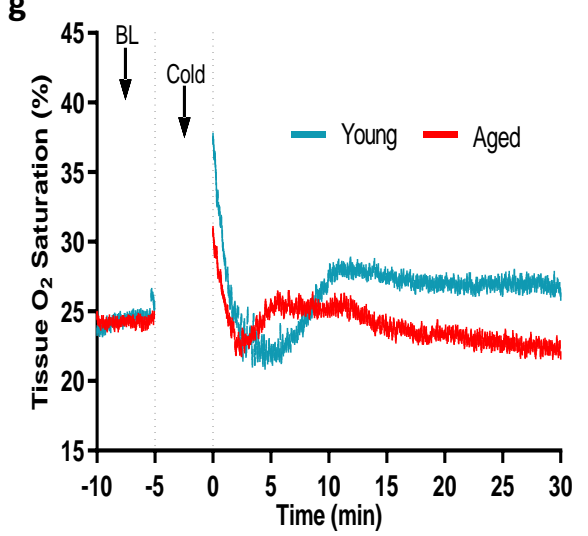

b

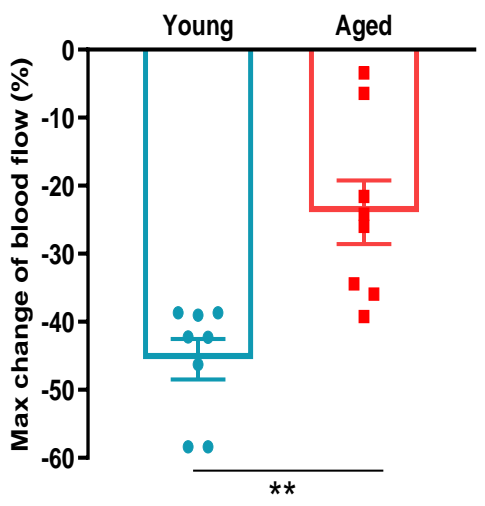

e

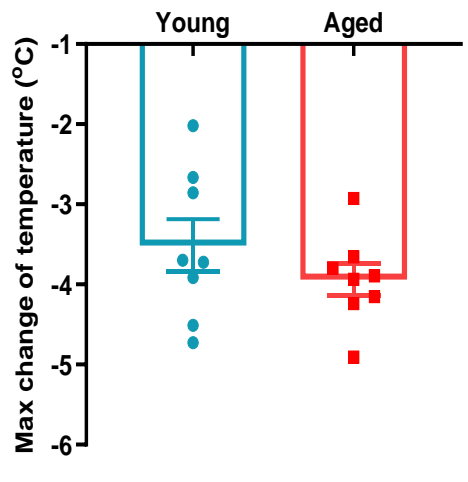

h

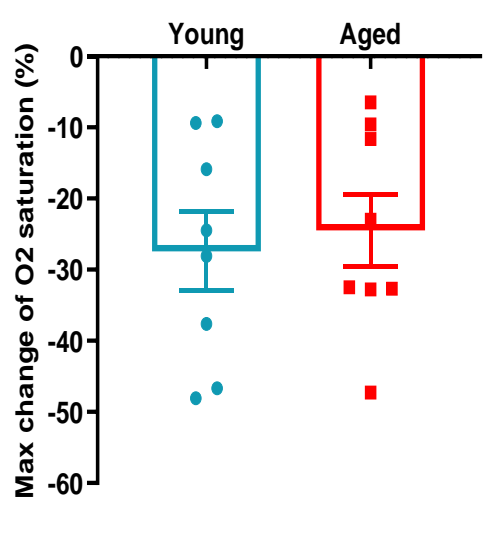

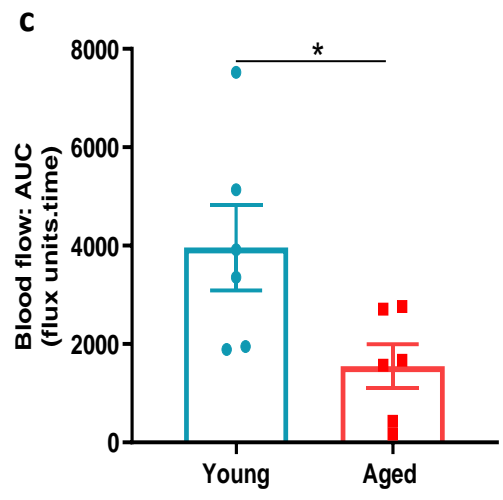

f

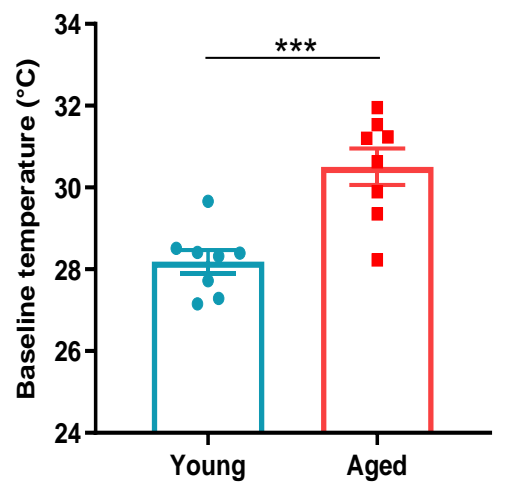

i

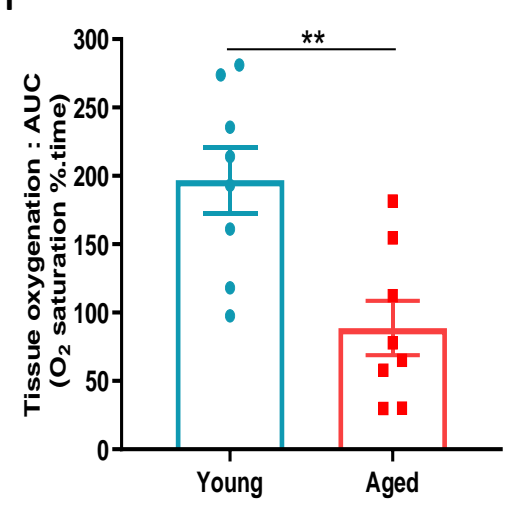

Figure 2: Blood flow, skin temperature and tissue oxygen saturation with cold treatment in ageing. (a) Mean blood flow trace of the vascular response with cold $\left(4^{\circ} \mathrm{C}\right)$ water treatment $(n=8)$. (b) \% change in hindpaw blood flow from baseline to $0-2$ min following cold treatment (maximum vasoconstriction). (c) The vasoconstriction response caused by cold water treatment represented by area under curve (AUC). (d) The mean blood flow ( \pm s.e.m.) recordings of hindpaw skin temperature with cold water treatment. (e) Maximum reduction in skin temperature following 5 min cold treatment. (f) The baseline skin temperature. (g) \% mean tissue oxygen saturation during cold water treatment. (h) \% maximum change in tissue oxygen saturation from baseline following cold water treatment (i) \% tissue oxygen saturation recovery after cold water treatment assessed by area under the curve. ( $\mathrm{BL}=$ baseline). Data is presented as mean and all error bars indicate s.e.m. ${ }^{*} p<0.05,{ }^{* *} p<0.01,{ }^{* * *} p<0.001$. (Two-tailed Student's t-test). 

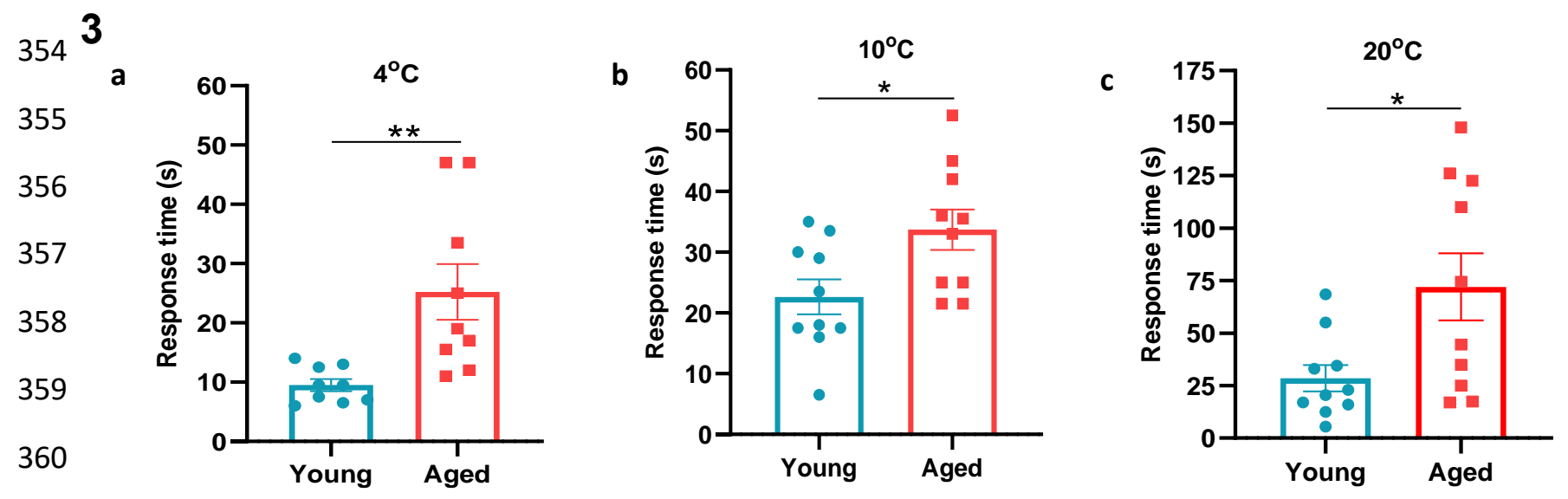

361

362

d

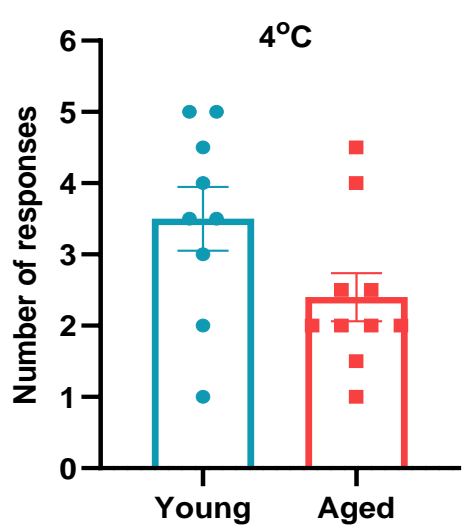

e
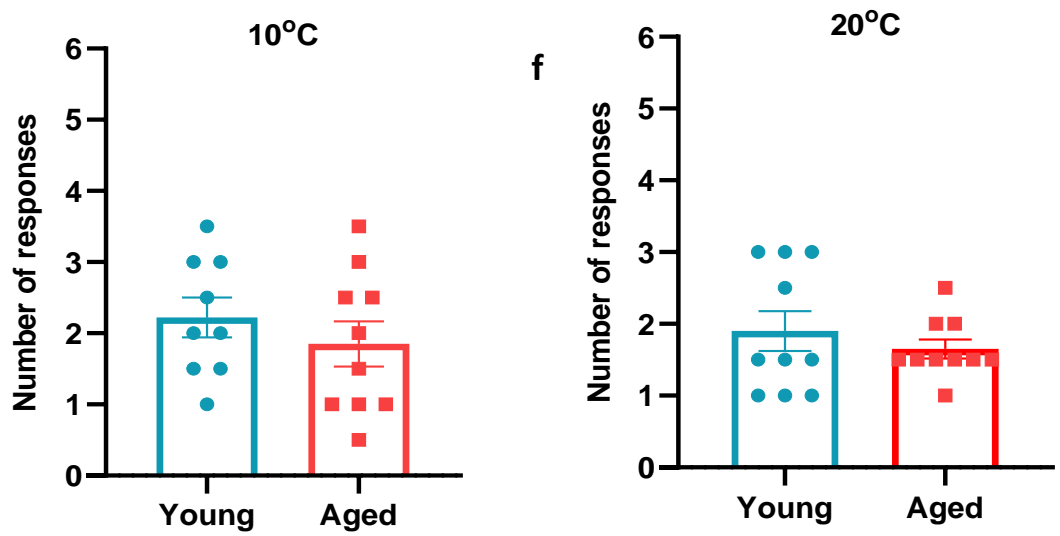

368

369

370

g $2507 \quad 30^{\circ} \mathrm{C}$

h
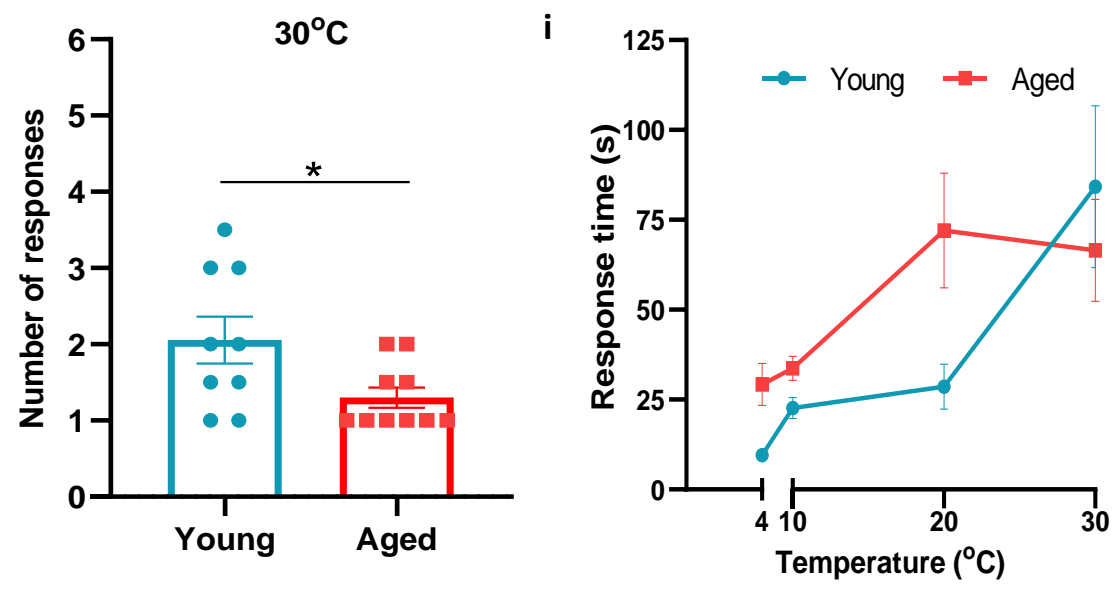

377

Figure 3: Behavioural analysis with cold plate in young and aged mice (a-c) Time of first response of mice to cold plate set at $4^{\circ} \mathrm{C}, 10^{\circ} \mathrm{C}$, and $20^{\circ} \mathrm{C}$. (d-f) The total number of responses from mice during the cold plate experiment at $4{ }^{\circ} \mathrm{C}, 10^{\circ} \mathrm{C}$, and $20^{\circ} \mathrm{C}$. (g-h) Time of first response of mice to cold plate set at $30^{\circ} \mathrm{C}$ and total number of responses. (i) Line graph illustrates the difference in mean response time at the four different temperatures the cold plate assay was performed, between young and aged mice. All results are shown as mean \pm s.e.m. ${ }^{*} p<0.05,{ }^{* *} p<0.01$. (Two-tailed Student's t-test). 
bioRxiv preprint doi: https://doi.org/10.1101/2021.05.10.443379; this version posted May 10, 2021. The copyright holder for this preprint (which was not certified by peer review) is the author/funder. All rights reserved. No reuse allowed without permission.
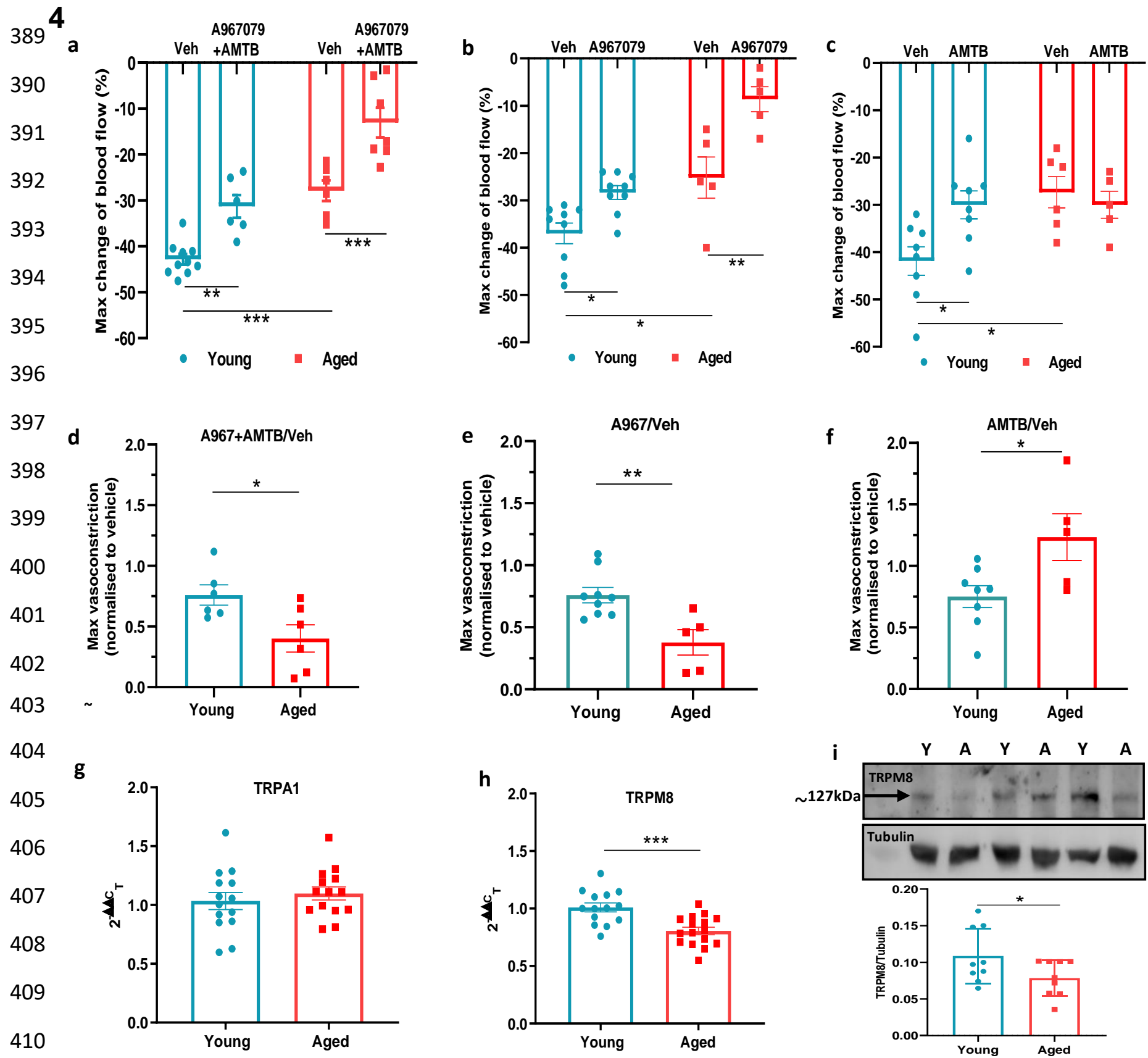

411

Figure 4: TRPA1 and TRPM8 are involved in cold-induced vascular response. Vascular responses with cold $\left(4^{\circ} \mathrm{C}\right)$ water treatment in mice pre-treated with combined TRPA1 antagonist A967079 $\left(100 \mathrm{mg} \mathrm{kg}^{-}\right.$ ${ }^{1}$ ) and TRPM8 antagonist AMTB (10 $\left.\mathrm{mg} \mathrm{kg}^{-1}\right)$, or vehicle control (Veh - 10\% DMSO, 10\% Tween in saline) i.p. $30 \mathrm{~min}$ before cold treatment. (a-c) \% change in hindpaw blood flow from baseline to $0-2 \mathrm{~min}$ following cold treatment (maximum vasoconstriction) in mice treated with combined antagonist (a) A967079+AMTB, (b) A967079, and (c) AMTB. (d-f) Maximum vasoconstriction caused by cold water treatment in mice treated with combined antagonist (d) A967079+AMTB, (e) A967079, and (f) AMTB normalized against vehicle treated mice. (g-h) RT-PCR CT analysis shows fold change of (g) TRPA1 and (h) TRPM8 normalized to three housekeeping genes in dorsal root ganglia (DRG). (i) Representative western blot of TRPM8 in DRG of young and aged mice and densitometric analysis normalized to Tubulin ( $Y=y$ oung, $A=a g e d)$. All results are shown as mean \pm s.e.m. ${ }^{*} p<0.05,{ }^{* *} p<0.01,{ }^{* * *} p<0.001$. (Two-way ANOVA with Tukey's post hoc test or Student's ttest). 
bioRxiv preprint doi: https://doi.org/10.1101/2021.05.10.443379; this version posted May 10, 2021. The copyright holder for this preprint (which was not certified by peer review) is the author/funder. All rights reserved. No reuse allowed without permission.

5

427

a

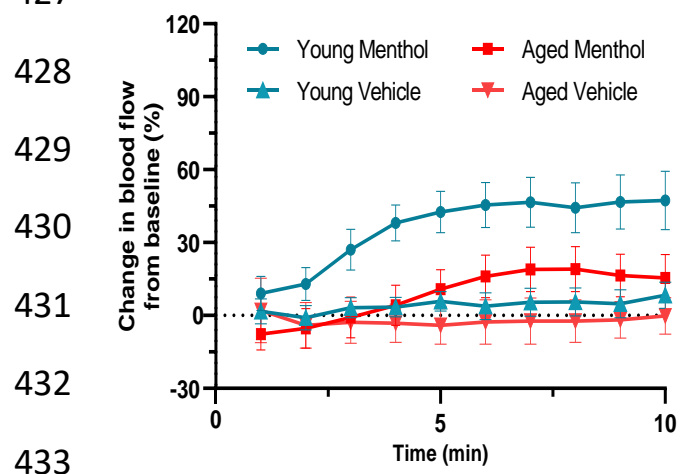

434

435

436

437

438

439

440

441

442

443

444

445

446

447

448

449

450

451

452

453

454

455

456

457

458

459

460

461

462

463 b

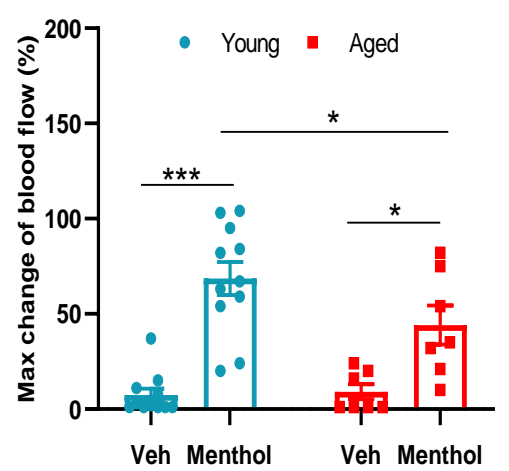

e

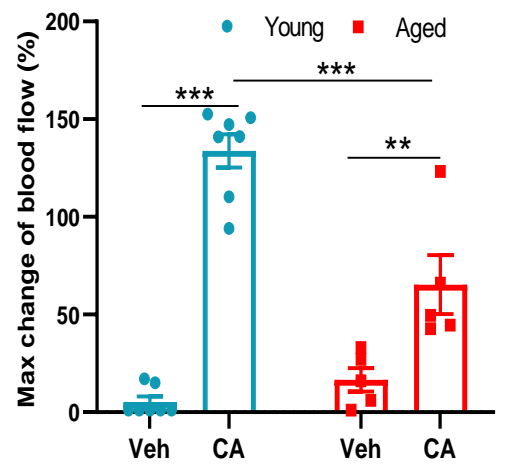

h

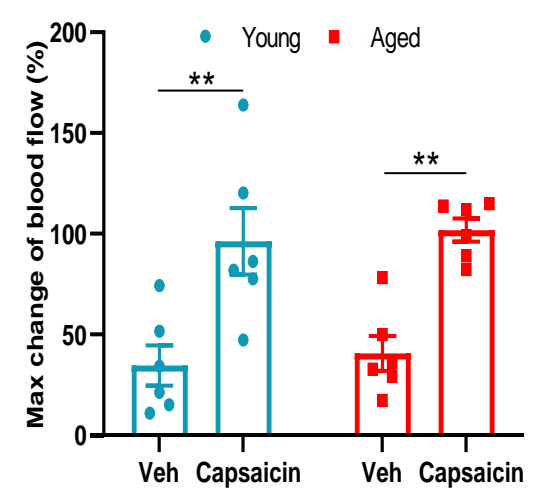

C

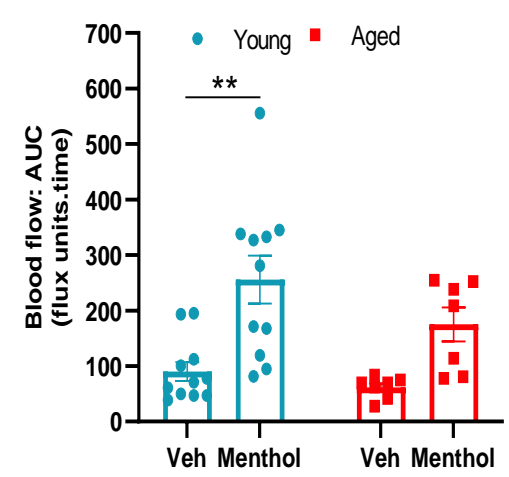

f

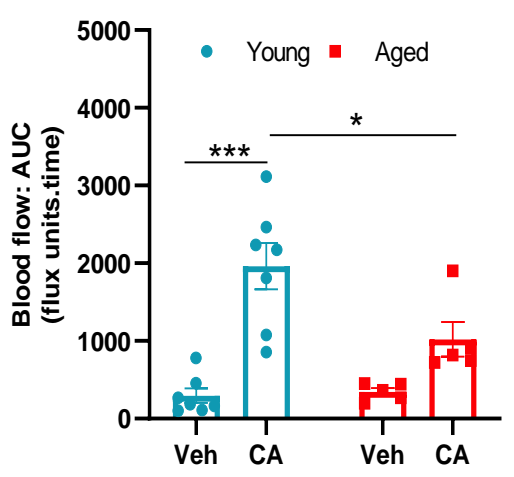

i

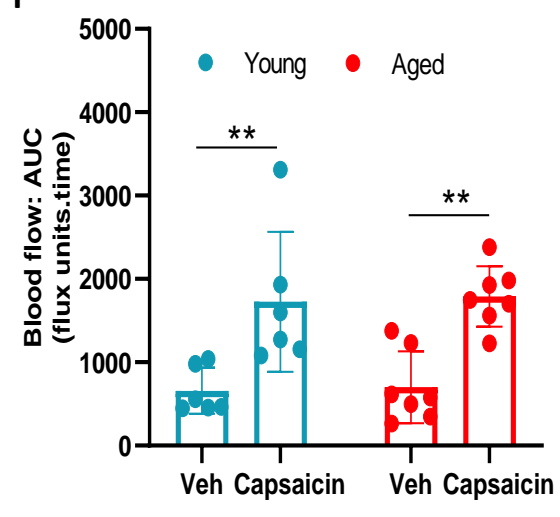

Figure 5: TRPA1 and TRPM8 activity deteriorates with ageing (a) Graph shows the \% mean \pm s.e.m. of blood flow change from baseline in response to topical application of menthol (10\%) and vehicle (Veh - 10\% DMSO in ethanol) in ear of young and aged mice. (b) \% maximum change in ear blood flow induced by menthol application in young and aged mice. (c) AUC analysis of \% blood flow increase from baseline after menthol application compared to vehicle. (d) Graph shows the \% mean \pm s.e.m. of blood flow change from baseline in response to topical application of cinnamaldehyde $(10 \% \mathrm{CA})$ and vehicle $(10 \%$ DMSO in ethanol) in ear of young and aged mice. (e) \% maximum change in ear blood flow induced by CA application in young and aged mice. (f) AUC analysis of \% blood flow increase from baseline after CA application compared to vehicle. (g) Graph shows the \% mean \pm s.e.m. of blood flow change from baseline in response to topical application of capsaicin (10\%) and vehicle (10\% DMSO in ethanol) in ear of young and aged mice. (h) \% maximum change in ear blood flow induced by capsaicin application in young and aged mice. (i) AUC analysis of \% blood flow increase from baseline after capsaicin application compared to vehicle. All results are shown as mean \pm s.e.m. ${ }^{*} \mathrm{p}<0.05,{ }^{* *} \mathrm{p}<0.01,{ }^{* *} \mathrm{p}<0.001$. (Two-way ANOVA with Tukey's post hoc test). 
4656.
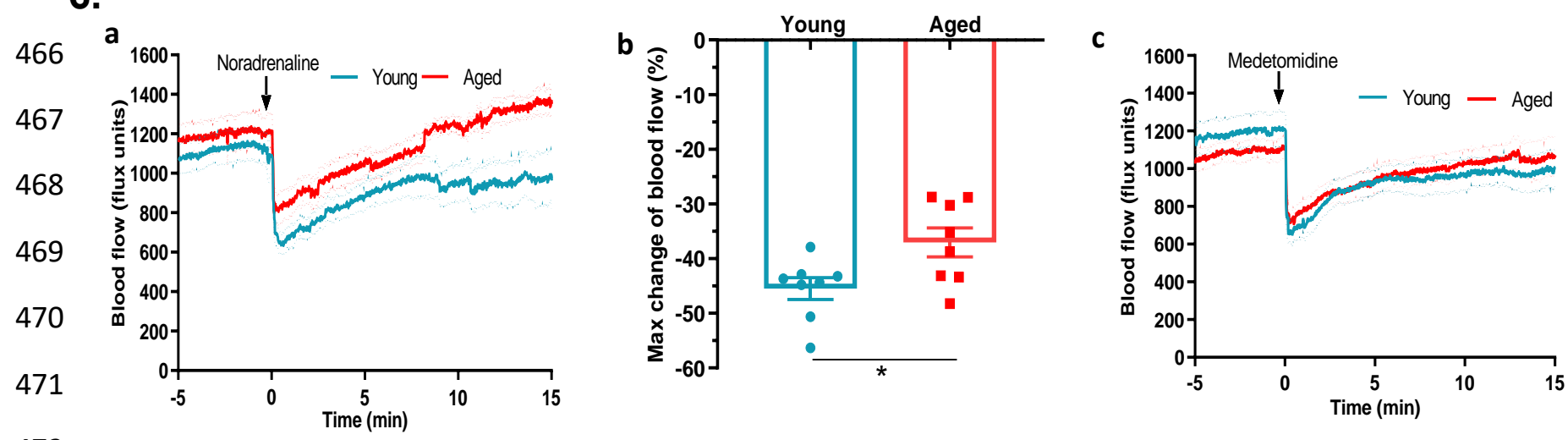

472

473

474

475

476

477

478

479

d

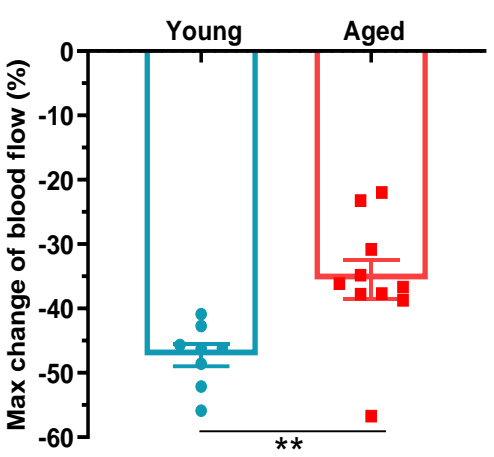

480

Figure 6: Dysfunctional sympathetic signalling in ageing (a) Graph shows the mean \pm s.e.m. blood flow in hindpaw with intraplantar injection of noradrenaline $(1.25 \mathrm{ng} / \mu \mathrm{l}$ in saline in $20 \mu \mathrm{l})$ in young and aged mice $(n=8)$. (b) \% maximum change in blood flow from baseline induced by noradrenaline (maximum vasoconstriction). (c) Graph shows the mean \pm s.e.m. blood flow in hindpaw with intraplantar injection of medetomidine $(1.25 \mathrm{ng} / \mu \mathrm{l}$ in saline in $20 \mu \mathrm{l})$ in young and aged mice $(n=8-10)(d) \%$ maximum change in blood flow from baseline induced by medetomidine (maximum vasoconstriction). (e) Representative western blot of alpha2C $\left(\alpha_{2 c}\right)$ adrenoceptor in mice hindpaw skin with densitometric analysis normalized to GAPDH. (f) Representative western blot of tyrosine hydroxylase (TH) in mice hindpaw skin with densitometric analysis normalized to GAPDH ( $Y=y$ oung, $A=a g e d)$. 
501

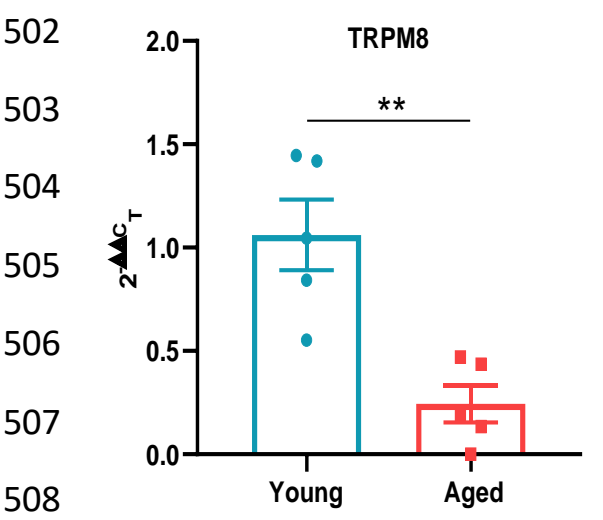

b

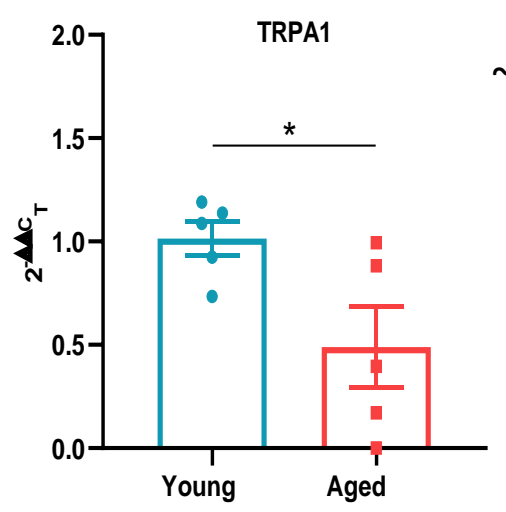

c

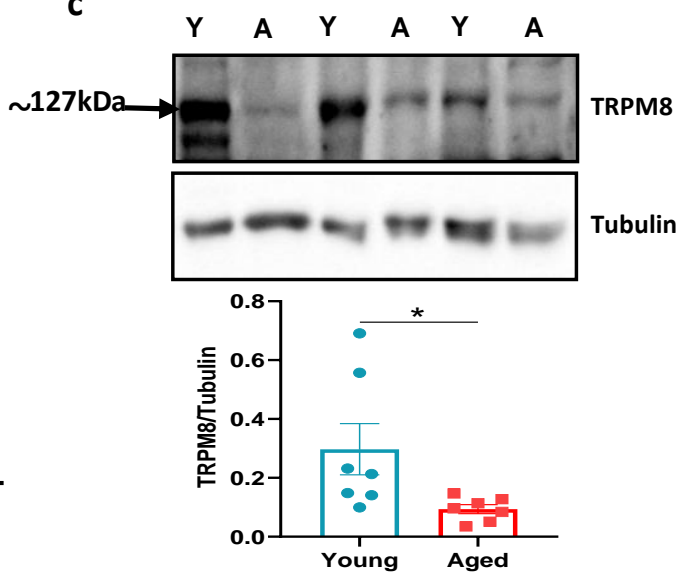

509

511

512

515

516

517

518

519

520

521

522

523

524

d
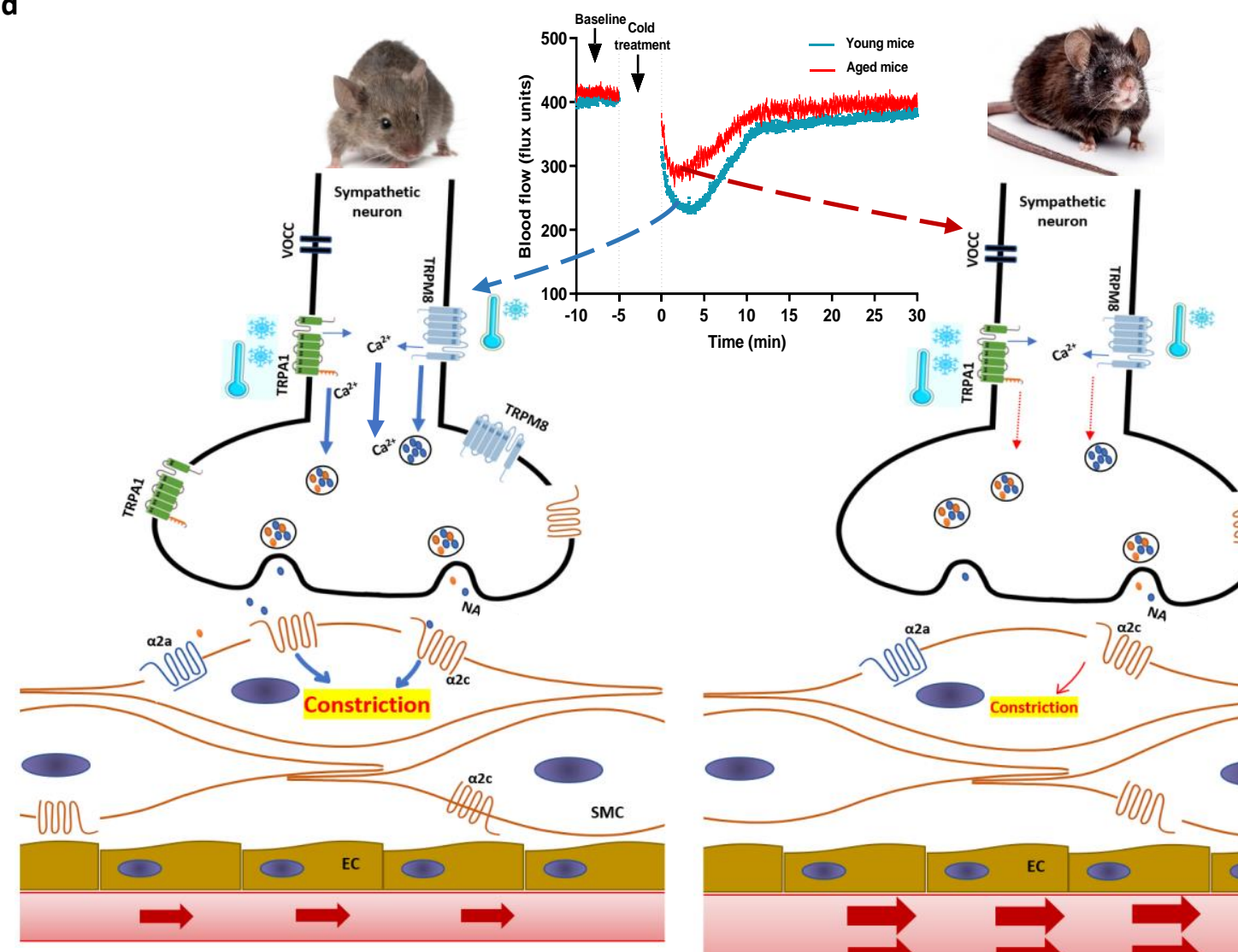

(8)
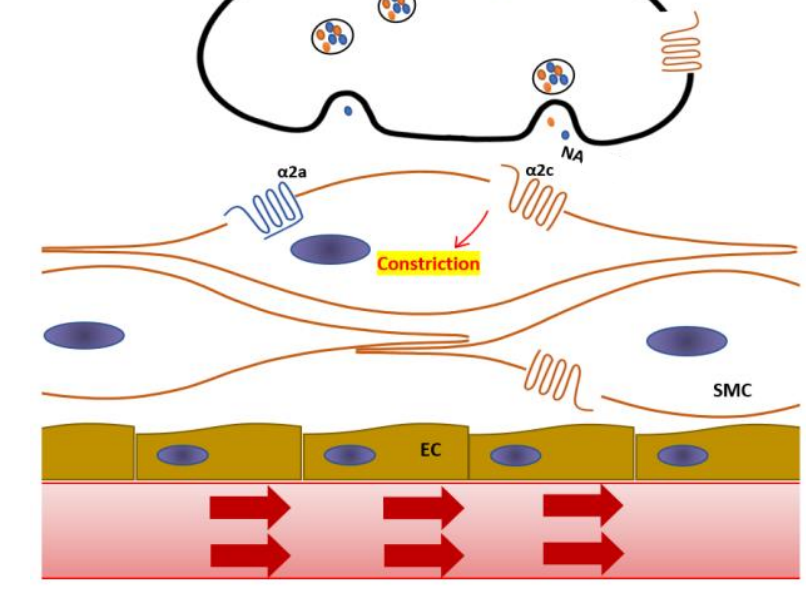

Figure 7: Sympathetic-sensory signalling and influence of ageing (a-b) RT-PCR CT analysis shows the expression and fold change of TRPA 1 and TRPM8 in young and aged sympathetic ganglia normalized to three housekeeping genes collected from the cervical and thoracic paravertebral region. (c) The western blot analysis of TRPM8 in sympathetic ganglia of young and aged mice. All results are shown as mean \pm s.e.m. ${ }^{*} p<0.05,{ }^{* *} p<0.01$. (Two-tailed Student's t-test). (d) Proposed cold-induced vasoconstriction signalling pathway in young and aged mice. The local cold exposure produces rapid vasoconstriction which is significantly blunted in the aged mice (see blood flow graph at top centre). Cold water $\left(4^{\circ} \mathrm{C}\right)$ exposure to hindpaw activates the cold receptors TRPA1 and TRPM8 in sympathetic nerves, which leads to increased intracellular calcium and release of NA. This signalling, however, is significantly downregulated in aged mice due to diminished expression of TRPA1/TRPM8 in sympathetic nerves. NA acts on the post-synaptic $\alpha_{2 c}$ adrenergic receptors on smooth muscle cells to mediate vasoconstriction. However, $\alpha_{2 c}$ adrenergic receptor are also significantly diminished in aged mice, which leads to reduced signalling. All of these factors contribute to an attenuated vascular cold response in aged mice compared to young mice. 
$\alpha_{2 c}$ - alpha2c adrenoceptor, $\alpha_{2 a}-$ alpha2a adrenoceptor, VOCC- voltage operated calcium channel, NA noradrenaline, $\mathrm{Ca}^{2+}$ - calcium, SMC- smooth muscle cell, EC - endothelial cell.

\section{Discussion}

The role of TRPA1 and TRPM8 as cold-sensitive thermoreceptors is established (Story et al., 2003, Bautista et al., 2007, Karashima et al., 2009, Peier et al., 2002, McKemy, Neuhausser \& Julius, 2002) and our research has demonstrated the essential role they play as vascular cold sensors (Aubdool et al., 2014, Pan et al., 2018). Much less was known about their activity in ageing, until this study. We provide a new insight into the changing roles of TRPA1 and TRPM8 in the vascular response to cold in ageing; the expression and activity of TRPM8 is significantly diminished, and to a lesser extent TRPA1 mediated signalling too.

The vascular response to the cold is a primary physiological response, which we have previously teased out the key mechanisms for, consisting of TRPA1/M8 initiated $\alpha_{2 c}$-mediated sympathetic vasoconstriction followed by TRPA1/M8 mediated sensory vascular relaxation after localised cold exposure in the mouse paw. Here, we show that the response is functionally deficient in ageing as measured by two different laser blood flow measurement techniques. Both components of the cold-induced vascular response were impaired in ageing with blunted vasoconstriction that will lead to increased heat loss, and a slower rate of recovery that may lead to cold-induced injuries (Keatinge, 1957, Roustit et al., 2011, Herrick, 2005). We were surprized that the diminished response was observed with even moderate ageing (1315 months old mice; equivalent to middle age in humans). However, the ageing nature of the mice was confirmed by the observation of increased expression of the established ageing markers p16 and p21 (Baker et al., 2016, Sharpless, Sherr, 2015, Hudgins et al., 2018). This finding is in keeping with the concept that although ageing-induced pathological conditions and frailty appear at a later age, the underlying physiological changes that manifest those conditions begin at a middle age of around 40 years old in humans. Indeed, this is when the brain volume and weight start to decline (Peters, 2006); cardiovascular functions begin to decline and elite athletes start to lose stamina (Pal et al., 2014, Mühlberg, Platt, 1999). We found that the baseline skin temperature was significantly higher in the aged mice than young mice, potentially due to greater heat loss from aged mice in keeping with the notion that it is harder to maintain core body temperature as ageing occurs. The tissue oxygen saturation was reduced during the vascular cold response but recovered substantially in the young compared to the aged mice. Overall, the findings show that the cold induced cutaneous vascular response is significantly diminished in ageing.

It is known that sensory modalities decline with ageing, but usually studies involve frail 24month old mice. Indeed, in one of the only studies of TRP thermo-receptors in ageing, to our knowledge, authors investigated the changes in TRPM8 expressing neurons in cornea with ageing and its relevance to dry eye disease (Alcalde et al., 2018). Here in our study, we delineate that activity and expression of one of the prominent sensory cold channels (TRPM8) diminishes with moderate ageing; relevant to the impaired vascular response to cold that we have observed. We designed experiments to evaluate the ability of the mouse to sense cold using a cold plate behavioural assay at innocuous cool (TRPM8 range) and noxious cold (TRPA1 range) temperatures. We observed a delayed latency to the cold response in moderately aged mice compared to young mice at three different cold temperatures, $4^{\circ} \mathrm{C}$, $10^{\circ} \mathrm{C}$, and $20^{\circ} \mathrm{C}$ implying impaired sensory signalling of TRPM 8 and TRPA 1 receptors. Importantly, the longest delayed latency was observed at $20^{\circ} \mathrm{C}$, which falls under the TRPM8 activation range implying that with ageing TRPM8 signalling deteriorates more, relative to that of TRPA1.

Using combined selective antagonists of TRPA1 and TRPM8, we show that blocking both receptors inhibits the cold-induced cutaneous vascular response in young mice, as expected. 
Intriguingly, the same treatment produced a relatively stronger inhibitory response in the aged mice. This implies that with ageing the cold signalling relies profoundly more on cold TRP channels. These results may also indicate that at younger ages other protein/s besides TRPA1 and TRPM8 play a crucial part in the cold signalling, but these activities begin to decline with ageing. This includes the $\alpha_{2 c}$ receptor as discussed below, although a range of other candidates have also been proposed (Zimmermann et al., 2011, Noël et al., 2009, Luiz et al., 2019, Gong et al., 2019). Importantly, when we investigated the effect of the TRPA1 antagonist alone, we observed a very similar inhibitory profile to that of the combination of TRPA1 and TRPM8 antagonists. However, the TRPM8 antagonist treatment alone, was effective in the young mice, but not in the aged mice. This provided key evidence that the activity of TRPM8 especially, is diminished in ageing. TRPM8 was discovered as a sensory receptor expressed in DRG and trigeminal ganglia (TG) that is activated by cool temperatures $\left(<28^{\circ} \mathrm{C}\right)($ McKemy, Neuhausser \& Julius, 2002); although the link with TRPA1 containing CGRP fibres is less well defined (Hondoh et al., 2010, Kobayashi et al., 2005). Since then, various reports have suggested that TRPM8 is expressed in a wider range of tissues and is involved in multiple physiological functions including thermoregulation (Moraes et al., 2017, Hirai et al., 2018, Yang et al., 2006). Indeed, it is established that the deletion/antagonism of TRPM8 increases heat loss and reduces core body temperature (Almeida et al., 2012, Reimúndez et al., 2018).

By this stage we had revealed a reduced expression and activity of TRPM8 in the vascular cold response and cold sensing. However, we have previously defined TRPA1 as an essential vascular sensor to cold, playing a major role in the cold induced vascular response alongside TRPM8 (Aubdool et al., 2014). Therefore, it was surprising to observe that expression of TRPA1, unlike TRPM8, did not diminish in the DRG with ageing, especially as the cold-sensing data from the cold plate at noxious cold temperatures revealed that the response is also impaired at noxious temperatures in ageing. To learn more, we studied the ability of the TRPA1 agonist cinnamaldehyde (CA) to increase cutaneous blood flow; as TRPA1 is localised to $\mathrm{CGRP}^{+}$sensory nerves (Aubdool et al., 2016). CA-induced vasodilation was significantly impaired in the aged mice compared to young, supporting the concept of impaired functional TRPA1 vascular responses in ageing. We observed a similar significantly blunted response with the TRPM8 agonist menthol in aged mice, although TRPM8 localisation to sensory nerves is more limited than that of TRPA1 (Kobayashi et al., 2005). This led us to question whether activity of all TRP receptors deteriorates with ageing, through investigating the non-cold sensing TRPV1 agonist capsaicin which activates predominantly CGRP ${ }^{+}$C-fibres (Story et al., 2003, Sharrad et al., 2015). In contrast to menthol and CA, capsaicin caused a similar level of increased blood flow in all mice regardless of age indicating TRPV1 activity does not deteriorate with ageing, and supporting our behaviour data at $30^{\circ} \mathrm{C}$, which falls outside TRPA1 and TRPM8 activation ranges. These results suggest that only the signalling of cold TRP receptors; TRPA1 and TRPM8 is impaired with ageing.

The cold-induced vasoconstriction phase is mediated by sympathetic drive comprising of noradrenergic nerves and this signalling has been shown to decline with ageing (Degroot, Kenney, 2007, Frank et al., 2000, Greaney, Alexander \& Kenney, 2015). Thus, we aimed to elucidate the sympathetic signalling in young and aged mice, which we began by investigating the effect of exogenous agonist NA. NA administered locally to the paw evoked cutaneous vasoconstriction in young mice that was significantly blunted in the aged mice, suggesting that NA-mediated response diminishes in aged mice. Nonetheless, NA is a non-selective agonist for all adrenoceptors, but peripheral cutaneous vasoconstriction is mediated via a adrenergic receptors (Drew, Whiting, 1979), with cold specific vasoconstriction primarily mediated via $\alpha_{2 c}$ adrenoceptors subtype (Bailey et al., 2004, Honda et al., 2007). Therefore, we used the selective $\alpha_{2}$ agonist medetomidine which induced vasoconstriction that was also significantly blunted in the aged mice. The result suggests that either $\alpha_{2 c}$ receptor sensitivity declines with ageing (Thompson, Holowatz \& Kenney, 2005) or $\alpha_{2 c}$ receptor number reduces with ageing which has been suggested to occur in ageing human saphenous vein (Hyland, Docherty, 
640

641

642

643

644

645

646

647

648

649

650

651

652

653

654

655

656

657

658

659

660

661

662

663

664

665

666

667

668

669

670

671

672

673

674

675

676

677

678

679

680

681

682

683

684

685

686

687

688

1985). In our study, we found a significant reduction in the expression of $\alpha_{2 c}$ adrenoceptors. We also investigated whether the level of NA or its synthesis was impaired in ageing and observed no difference in the level of tyrosine hydroxylase (including the active form of phosphorylated tyrosine hydroxylase), the enzyme involved in the rate limiting synthesis of NA production. This indicates that NA synthesis is not affected in ageing.

The cold-induced vascular response is perceived as a reflex where peripheral sensory nerves sense the cold stimulus and send information to the central nervous system (CNS). In turn, the CNS processes the information and produces an appropriate response via activation of sympathetic nerves to cause vasoconstriction in skin (Chotani et al., 2000). Classically, it is established that sensory receptors TRPA 1 and TRPM8 that sense cold reside in sensory nerves and alpha-adrenergic receptors reside in sympathetic nerves and smooth muscle cells to modulate vasoconstriction. However, we have previously shown that the cold-induced vasoconstrictor response occurs when the sensory C-fibre component is removed with resiniferatoxin treatment (Aubdool et al., 2014). This clear result raises the possibility that the cold sensitive proteins TRPA 1 and TRPM 8 may be expressed in other tissues besides sensory nerves and modulate the vascular tone, as suggested to be the case in some organs (Earley, 2012, Johnson et al., 2005, Yang et al., 2006). The sensory nerves and sympathetic nerves are known to have close proximation around blood vessels and have a reciprocal trophic influence (Terenghi et al., 1986). Thus, we questioned whether cold TRP channels were expressed on sympathetic nerves to directly modulate the vascular tone. We found that both TRPA1 and TRPM8 are expressed in the sympathetic ganglia (SG) collected from the cervical and thoracic paravertebral regions, in keeping with previous studies (Smith et al., 2004), but debated. Furthermore, the expression of both receptors were significantly diminished in the SG collected from the aged mice compared to young mice. Collectively, these findings suggest that cold stimuli activate TRPA1 and TRPM8 channels on sympathetic nerves, which induces calcium-dependent release of vesicles containing NA into the synaptic cleft where they activate the $\alpha_{2 c}$ adrenoceptor on smooth muscle cells to mediate vasoconstriction (Fig $7 d$ ). This signalling cascade has been shown in PC12 cells, which is regularly used as in-vitro model for sympathetic neurons (Smith et al., 2004, Peixoto-Neves, Soni \& Adebiyi, 2018, Yoshimura, Nakagawa \& Endo, 2016). It indicates a potential for sympathetic-sensory interactive signalling in skin, which weakens as ageing progresses in turn affecting the sensitivity of the vascular response to cold.

To conclude, we have revealed that the cold induced defensive responses decline with ageing. There is an impairment in the sympathetic vasoconstrictor pathway concomitant with a functional deterioration and molecular loss of TRPM8 and TRPA1 signalling as well as diminished $\alpha_{2 c}$ adrenergic receptor expression and activity. We consider that the finding of diminished TRPM8 expression with ageing is indicative of a major influence of this channel that would lead to the impaired cold induced vascular response in ageing.

\section{Methods}

Animals. Female CD1 mice used in this study were either bred in the Biological Services Unit, King's College London or purchased from Charles River (Kent, UK). The animals were housed in a climatically controlled environment with an ambient temperature of $22^{\circ} \mathrm{C}$, including a 12 hour light/dark (7am-7pm) cycle with free access to drinking water and standard chow ad libitum. Young mice were 2-3 months old and aged mice were 13-16 months old. All experiments were performed according to the Animal Care and Ethics committee at King's College London, in addition to the regulations set by the UK home office Animals (Scientific Procedures) act 1986. Experiments using animals were designed and reported in line with the ARRIVE guidelines, which form the NC3Rs initiative. Animals were randomly assigned to 
689

690

691

692

693

694

695

696

697

698

699

700

701

702

703

704

705

706

707

708

709

710

711

712

713

714

715

716

717

718

719

720

721

722

723

724

725

726

727

728

729

730

731

732

733

734

735

different groups and the investigator was blinded to drug treatments and where possible to the age of the animals.

Cutaneous blood flow measurement by full-field laser perfusion imager. Mice were terminally anaesthetized with i.p. injection of ketamine $\left(75 \mathrm{mg} \mathrm{kg}^{-1}\right)$ and medetomidine $(1 \mathrm{mg}$ $\left.\mathrm{kg}^{-1}\right)$. Wherever possible to comply with the NC3Rs reduction guidelines, experiments were designed using recovery anaesthesia, which was either s.c. $150 \mathrm{mg} \mathrm{kg}^{-1}$ ketamine and 4.25 $\mathrm{mg} \mathrm{kg}^{-1}$ xylazine, or isoflurane gas. $5 \%$ isoflurane (in oxygen) was used to induce anaesthesia, which was followed by $2 \%$ for maintenance during the experimental procedure. Full-field Laser Perfusion Imager (FLPI, Moor Instruments, UK) was used to measure blood flow in the hind paw or the ear of the mice. The mice were placed in a ventral position on a heating mat to maintain core body temperature at $37^{\circ} \mathrm{C}$ during blood flow measurement. For the cold-induced blood flow measurement in hindpaw, after anaesthesia, the blood flow was measured on the plantar surface of hindpaw for $5 \mathrm{~min}$ as baseline measurement. Then, the ipsilateral hindpaw at the level between tibia and calcaneus was immersed in cold water $\left(4^{\circ} \mathrm{C}\right.$ for $\left.5 \mathrm{~min}\right)$ for cold exposure. After the cold treatment, mice were placed back on the heating mat $\left(37^{\circ} \mathrm{C}\right)$ to measure blood flow recovery for $30 \mathrm{~min}$. The FLPI uses laser light to produce speckle pattern that gets interfered by blood flow which is measured as arbitrary flux units (X10 ${ }^{3}$ flux units). For the agonist-induced blood flow measurement in ear, after anaesthesia, the blood flow was measured for $5 \mathrm{~min}$ as baseline recording. $10 \mu \mathrm{l}$ of either cinnamaldehyde (10\%), menthol $(10 \%)$, or capsaicin $(10 \%)$ was topically applied to both sides of the ipsilateral ear and $10 \mu \mathrm{l}$ vehicle solution (10\% DMSO in ethanol) was applied to the contralateral ear. Then blood flow was measured for 30 min after cinnamaldehyde and capsaicin treatment and for 10 min after menthol treatment. All treatments produced a gradual increase in blood flow. For $\mathrm{NA} /$ medetomidine-induced blood flow measurement in hindpaw, after anaesthesia, blood flow was measured on the plantar surface for $5 \mathrm{~min}$ as baseline recording. Intraplantar injection of $\mathrm{NA} /$ medetomidine $(1.25 \mathrm{ng} / \mathrm{ul})$ was performed and blood flow was measured for $15 \mathrm{~min}$.

Cutaneous blood flow, temperature and oxygen saturation measurement by laser Doppler techniques. A probe connected to the moorVMS-LDF (Laser Doppler Perfusion and Temperature Monitor) and moorVMS-OXY (Tissue Oxygen and Temperature Monitor) (Moor Instruments) was used to simultaneously measure blood flow, temperature and tissue oxygen saturation in a small, localized area ( $\sim 5 \mathrm{~mm}$ diameter) on the plantar surface of the ipsilateral hind paw (central region immediately adjacent to the digits). The probe was held on a retort stand clamp $1 \mathrm{~mm}$ above the skin surface. After inducing anaesthesia with i.p. injection of ketamine $\left(75 \mathrm{mg} \mathrm{kg}^{-1}\right)$ and medetomidine $\left(1 \mathrm{mg} \mathrm{kg}^{-1}\right)$, the blood flow was measured (baseline recording) on the plantar surface central area immediately adjacent to the digits for $5 \mathrm{~min}$. The ipsilateral hindpaw was immersed in cold water $\left(4^{\circ} \mathrm{C}\right.$ for $\left.5 \mathrm{~min}\right)$ at the level between tibia and calcaneus. After the cold treatment, mice were placed back on the heating mat $\left(37^{\circ} \mathrm{C}\right)$ to record all measurements during the recovery period for $30 \mathrm{~min}$. The blood flow was measured using doppler technique and expressed in arbitrary flux units, and tissue oxygen saturation was measured using white light spectroscopy method.

Drugs and reagents. The TRPA1 antagonist A967079 ((1E,3E)-1-(4-Fluorophenyl)-2-methyl1-pentene-3-one oxime) (Alomone Labs, \# A-225) was dissolved in 10\% DMSO, 10\% Tween80 in saline. The TRPM8 antagonist AMTB (N-(3-aminopropyl)-2-[(3-methylphenyl) methyl] oxy-N-(2-thienylmethyl) benzamide hydrochloride salt) (Alomone Labs, \#A-305) was dissolved in $10 \%$ DMSO in saline. Both antagonists were administered i.p. $30 \mathrm{~min}$ before the cold treatment. Cinnamaldehyde (Sigma Aldrich, \#W228613, >95\% purity), menthol (Alfa Aesar, \#A18098, 98\% purity), capsaicin (Sigma Aldrich, \#M2028, >95\% purity) were prepared with 
$10 \%$ DMSO in ethanol solution. $1.25 \mathrm{ng} / \mu \mathrm{l}$ NA (Sigma) and $1.25 \mathrm{ng} / \mu \mathrm{l}$ medetomidine (Orion Pharma) were administered with intraplantar injection in $20 \mu$ l saline.

Behavioural testing using the cold plate. The nociceptive cold sensitivity response of mice was tested using a hot/cold thermal plate (Ugo Basile 35100). A quick temperature noncontact infrared thermometer (Linear labs) was used to confirm the set temperature of the plate before each experiment. Prior to the experiments, mice were acclimatised to the room for 30 min for 3 days, and the thermal plate by individually placing them on the plate at room temperature for 2 min on each of the 3 days. At the start of the experiment, the plate was set to the chosen temperature $\left(4^{\circ} \mathrm{C}, 10^{\circ} \mathrm{C}, 20^{\circ} \mathrm{C}\right.$ and $\left.30^{\circ} \mathrm{C}\right)$ and each mouse was placed individually onto the plate in turn. The cold response was detected as either paw licking or paw withdrawal/jumping and the total number of responses observed within $1 \mathrm{~min}$ (for $4^{\circ} \mathrm{C}$ and $\left.10^{\circ} \mathrm{C}\right)$ and $5 \mathrm{~min}\left(20^{\circ} \mathrm{C}\right.$ and $\left.30^{\circ} \mathrm{C}\right)$ were tallied. Each temperature was repeated twice on different days to obtain an average which was used to plot the final graph.

Quantitative polymerase chain reaction. Real time PCR (RT-qPCR) was used to quantify changes in mRNA collected from pooled dorsal root ganglia (DRG), brown adipose tissue (BAT) and sympathetic ganglia collected from thoracic paravertebral region. The total RNA was isolated and purified according to manufacturer's instructions using the RNeasy Micro Kit (Qiagen, \#74004). The RNA concentration and absorbance ratio (A260/280 and A260/230) were measured using Nanodrop 2000 spectrophotometer. 500ng of purified RNA was reverse transcribed using SuperScript ViLO cDNA synthesis kit (Thermo fisher scientific, \#11754050). qPCR was performed with 10ng of cDNA using PowerUp SYBR Green master mix kit (Thermo fisher Scientific, \#A25780) in 7900HT Real-Time PCR machine (Applied Biosystems, USA). All primers (Supplementary table 1) were designed using Primer-BLAST software (NCBI) according to MIQE guidelines and checked on the primer stat website. (http://www.bioinformatics.org/sms2/pcr primer stats.html). The melting curve analysis was performed after reactions to confirm specificity of the primers. The analysis was performed using delta delta CT method and expressed as fold change normalized to the average of three housekeeping genes.

Western blotting. The western blotting analysis was performed as previously described (Aubdool et al., 2014). The tissue was lysed with SDS lysis buffer which was made up with inhibitors of both phosphatases and proteases (1 tablet per 10ml, \#4693159001 + \#4906845001, Sig-ma-Aldrich). The tissue was then homogenised using a tissue lyser (Qiagen, \#85300). The protein concentration was determined using the Bradford protein dye

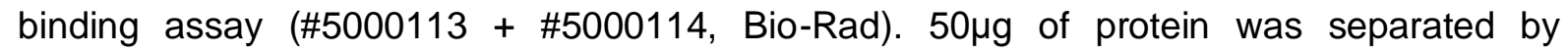
electrophoresis in an SDS-polyacrylamide gel which was then transferred using the semi dry method, onto PVDF membranes. The membrane was incubated in a blocking buffer made up of $5 \%$ BSA in Phosphate-buffered saline- tween (PBS-T) (0.1\% Tween). The membrane was blocked for $1 \mathrm{hr}$ in RT except for TRPM8 which was blocked for $2.5 \mathrm{hr}$ as per manufacturer's instruction. The membranes with primary antibodies were incubated overnight at $4^{\circ} \mathrm{C}$. Following the washing step with PBS-T, the membranes were probed with secondary antibody (Horseradish peroxidase conjugated) (1:2000 dilution, \#AP132P Sigma) for $1 \mathrm{hr}$ at RT. The enhanced chemiluminescence (ECL, Piercenet) was used for visual development of the membranes inside a gel doc system. Bands were normalised to housekeeping genes $\alpha$-tubulin (1:2000, \#MAB1864, Merck Millipore), GAPDH (1:2000, \#PA1987, Thermofisher) and $\beta$-actin (1:2000, \#A5441, Sigma Aldrich). Quantitative western blot analysis was performed using Image $\mathrm{J}(\mathrm{NIH}, \mathrm{USA})$. The primary antibodies were made in 3\% PBST solution at 1:500 dilution for TRPM8 (Alomone Labs \#ACC049), 1:1000 dilution for $\alpha_{2 c}$ adrenergic receptor (Bio-Techne 
\#NB100-93554), phospho TH (Bio-Techne \#NB300-173), total TH (Bio-Techne \#NB300-109), p21 (Santa Cruz \#sc-6246).

Experimental design and data analysis. The majority of the experiments conducted in this study consisted of two groups (young/aged) or four groups with drug treatments (young/aged and vehicle/drug), therefore the power analysis from our lab(Aubdool et al., 2014) with a power of $80 \%(0.8)$ for a confidence of $5 \%(0.05)$ recommended $n=8$, which was strictly adhered to where possible. The order of the mice (young or aged) and treatments (vehicle/drug) received were randomised during experimental protocols. Data was analysed using either two-tailed Student's t-tests or two-way ANOVA followed by Tukey's post hoc test. All column data are plotted as dot plots to show variability and $n$ numbers for each data set. All data are expressed as mean \pm SEM. $p<0.05$ was considered to represent a significant difference. GraphPad Prism (version 8) was used as statistics software for analysis.

\section{Acknowledgements}

This work was primarily funded by BBSRC (BB/P005616/1). It was also supported in part by Versus Arthritis (ARUK21524) and British Heart Foundation (BHF- FS/19/42/34527 and $P G / 12 / 34 / 29557)$.

\section{Author contributions}

DT and SDB designed the research. DT, JV, BB, FA, SL and SN carried out research. DT, BB and SL performed data analysis. XK helped with blinding and data analysis. DT, BB and SDB drafted the manuscript and all authors contributed to finalizing the manuscript.

\section{Competing interests}

The authors declare no competing interests.

\section{References.}

Alcalde, I., Íñigo-Portugués, A., González-González, O., Almaraz, L., Artime, E., MorenillaPalao, C., Gallar, J., Viana, F., Merayo-Lloves, J. \& Belmonte, C. 2018, "Morphological and functional changes in TRPM8-expressing corneal cold thermoreceptor neurons during aging and their impact on tearing in mice", Journal of Comparative Neurology, vol. 526, no. 11, pp. 1859-187410.1002/cne.24454.

Almeida, M.C., Hew-Butler, T., Soriano, R.N., Rao, S., Wang, W., Wang, J., Tamayo, N., Oliveira, D.L., Nucci, T.B., Aryal, P., Garami, A., Bautista, D., Gavva, N.R. \& Romanovsky, A.A. 2012, "Pharmacological Blockade of the Cold Receptor TRPM8 Attenuates Autonomic and Behavioral Cold Defenses and Decreases Deep Body Temperature", The Journal of Neuroscience, vol. 32, no. 6, pp. 2086209910.1523/JNEUROSCI.5606-11.2012.

Aubdool, A.A., Graepel, R., Kodji, X., Alawi, K.M., Bodkin, J.V., Srivastava, S., Gentry, C., Heads, R., Grant, A.D., Fernandes, E.S., Bevan, S. \& Brain, S.D. 2014, "TRPA1 is essential for the vascular response to environmental cold exposure", Nature Communications, vol. 5, pp. 573210.1038/ncomms6732. 
Aubdool, A.A., Kodji, X., Abdul-Kader, N., Heads, R., Fernandes, E.S., Bevan, S. \& Brain, S.D. 2016, "TRPA1 activation leads to neurogenic vasodilatation: involvement of reactive oxygen nitrogen species in addition to CGRP and NO", British Journal of Pharmacology, vol. 173, no. 15, pp. 2419-243310.1111/bph.13519.

Bailey, S.R., Eid, A.H., Mitra, S., Flavahan, S. \& Flavahan, N.A. 2004, "Rho kinase mediates cold-induced constriction of cutaneous arteries: role of alpha2C-adrenoceptor translocation", Circulation Research, vol. 94, no. 10, pp. 1367137410.1161/01.RES.0000128407.45014.58.

Baker, D.J., Childs, B.G., Durik, M., Wijers, M.E., Sieben, C.J., Zhong, J., Saltness, R.A., Jeganathan, K.B., Verzosa, G.C., Pezeshki, A., Khazaie, K., Miller, J.D. \& van Deursen, J.M. 2016, "Naturally occurring p16(Ink4a)-positive cells shorten healthy lifespan", Nature, vol. 530, no. 7589, pp. 184-18910.1038/nature16932.

Bautista, D.M., Siemens, J., Glazer, J.M., Tsuruda, P.R., Basbaum, A.I., Stucky, C.L., Jordt, S. \& Julius, D. 2007, "The menthol receptor TRPM8 is the principal detector of environmental cold", Nature, vol. 448, no. 7150, pp. 204-20810.1038/nature05910.

Billeter, A.T., Hohmann, S.F., Druen, D., Cannon, R. \& Polk, H.C. 2014, "Unintentional perioperative hypothermia is associated with severe complications and high mortality in elective operations", Surgery, vol. 156, no. 5, pp. 1245125210.1016/j.surg.2014.04.024.

Chotani, M.A., Flavahan, S., Mitra, S., Daunt, D. \& Flavahan, N.A. 2000, "Silent alpha(2C)adrenergic receptors enable cold-induced vasoconstriction in cutaneous arteries", American Journal of Physiology. Heart and Circulatory Physiology, vol. 278, no. 4, pp. 107510.1152/ajpheart.2000.278.4.H1075.

Craighead, D.H., McCartney, N.B., Tumlinson, J.H. \& Alexander, L.M. 2017, "Mechanisms and time course of menthol-induced cutaneous vasodilation", Microvascular research, vol. 110, pp. 43-4710.1016/j.mvr.2016.11.008.

Daanen, H.A.M. \& van der Struijs, Norbert R. 2005, "Resistance Index of Frostbite as a predictor of cold injury in arctic operations", Aviation, Space, and Environmental Medicine, vol. 76, no. 12, pp. 1119-1122.

Degroot, D.W. \& Kenney, W.L. 2007, "Impaired defense of core temperature in aged humans during mild cold stress", American Journal of Physiology. Regulatory, Integrative and Comparative Physiology, vol. 292, no. 1, pp. 10310.1152/ajpregu.00074.2006.

Dhaka, A., Murray, A.N., Mathur, J., Earley, T.J., Petrus, M.J. \& Patapoutian, A. 2007, "TRPM8 is required for cold sensation in mice", Neuron, vol. 54, no. 3, pp. 37137810.1016/j.neuron.2007.02.024.

Drew, G.M. \& Whiting, S.B. 1979, "Evidence for two distinct types of postsynaptic alphaadrenoceptor in vascular smooth muscle in vivo", British Journal of Pharmacology, vol. 67, no. 2, pp. 207-21510.1111/j.1476-5381.1979.tb08668.x.

Dutta, S. \& Sengupta, P. 2016, "Men and mice: Relating their ages", Life Sciences, vol. 152, pp. 244-24810.1016/.lfss.2015.10.025.

Earley, S. 2012, "TRPA1 channels in the vasculature", British Journal of Pharmacology, vol. 167, no. 1, pp. 13-2210.1111/j.1476-5381.2012.02018.x. 
868

869

870

871

872

873

874

875

876

877

878

879

880

881

882

883

884

885

886

887

888

889

890

891

892

893

894

895

896

897

898

899

900

901

902

903

904

905

906

907

908

909

910

Frank, S.M., Raja, S.N., Bulcao, C. \& Goldstein, D.S. 2000, "Age-related thermoregulatory differences during core cooling in humans", American Journal of Physiology. Regulatory, Integrative and Comparative Physiology, vol. 279, no. 1, pp. 34910.1152/ajpregu.2000.279.1.R349.

Gavva, N.R., Davis, C., Lehto, S.G., Rao, S., Wang, W. \& Zhu, D.X. 2012, "Transient Receptor Potential Melastatin 8 (TRPM8) Channels are Involved in Body Temperature Regulation", Molecular Pain, vol. 8, no. 36, pp. 1744-806910.1186/1744-8069-8-36.

Gentry, C., Stoakley, N., Andersson, D.A. \& Bevan, S. 2010, "The roles of iPLA2, TRPM8 and TRPA1 in chemically induced cold hypersensitivity", Molecular Pain, vol. 6, pp. 410.1186/1744-8069-6-4.

Gong, J., Liu, J., Ronan, E.A., He, F., Cai, W., Fatima, M., Zhang, W., Lee, H., Li, Z., Kim, G., Pipe, K.P., Duan, B., Liu, J. \& Xu, X.Z.S. 2019, "A Cold-Sensing Receptor Encoded by a Glutamate Receptor Gene", Cell, vol. 178, no. 6, pp. 1375138610.1016/j.cell.2019.07.034.

Gouin, O., L'Herondelle, K., Lebonvallet, N., Le Gall-lanotto, C., Sakka, M., Buhé, V., PléeGautier, E., Carré, J., Lefeuvre, L., Misery, L. \& Le Garrec, R. 2017, "TRPV1 and TRPA1 in cutaneous neurogenic and chronic inflammation: pro-inflammatory response induced by their activation and their sensitization", Protein \& Cell, vol. 8, no. 9, pp. 64466110.1007/s13238-017-0395-5.

Grant, A.D., Pinter, E., Salmon, A.L. \& Brain, S.D. 2005, "An examination of neurogenic mechanisms involved in mustard oil-induced inflammation in the mouse", European Journal of Pharmacology, vol. 507, no. 1-3, pp. 273-28010.1016/j.ejphar.2004.11.026.

Greaney, J.L., Alexander, L.M. \& Kenney, W.L. 2015, "Sympathetic control of reflex cutaneous vasoconstriction in human aging", Journal of Applied Physiology (Bethesda, Md.: 1985), vol. 119, no. 7, pp. 771-78210.1152/japplphysiol.00527.2015.

Guergova, S. \& Dufour, A. 2011, "Thermal sensitivity in the elderly: a review", Ageing Research Reviews, vol. 10, no. 1, pp. 80-9210.1016/j.arr.2010.04.009.

Herrick, A.L. 2005, "Pathogenesis of Raynaud's phenomenon", Rheumatology (Oxford, England), vol. 44, no. 5, pp. 587-59610.1093/rheumatology/keh552.

Hirai, A., Aung, N.Y., Ohe, R., Nishida, A., Kato, T., Meng, H., Ishizawa, K., Fujii, J. \& Yamakawa, M. 2018, "Expression of TRPM8 in human reactive lymphoid tissues and mature B-cell neoplasms", Oncology Letters, vol. 16, no. 5, pp. 5930593810.3892/ol.2018.9386.

Holowatz, L.A., Thompson-Torgerson, C. \& Kenney, W.L. 2010, "Aging and the control of human skin blood flow", Frontiers in bioscience : a journal and virtual library, vol. 15, pp. 718-739.

Honda, M., Suzuki, M., Nakayama, K. \& Ishikawa, T. 2007, "Role of a2C-adrenoceptors in the reduction of skin blood flow induced by local cooling in mice", British Journal of Pharmacology, vol. 152, no. 1, pp. 91-10010.1038/sj.bjp.0707380.

Hondoh, A., Ishida, Y., Ugawa, S., Ueda, T., Shibata, Y., Yamada, T., Shikano, M., Murakami, S. \& Shimada, S. 2010, "Distinct expression of cold receptors (TRPM8 and TRPA1) in the rat nodose-petrosal ganglion complex", Brain Research, vol. 1319, pp. 60-6910.1016/j.brainres.2010.01.016. 
911

912

913

914

915

916

917

918

919

920

921

922

923

924

925

926

927

928

Hudgins, A.D., Tazearslan, C., Tare, A., Zhu, Y., Huffman, D. \& Suh, Y. 2018, "Age- and Tissue-Specific Expression of Senescence Biomarkers in Mice", Frontiers in Genetics, vol. 9, pp. 5910.3389/fgene.2018.00059.

Hyland, L. \& Docherty, J.R. 1985, "An investigation of age-related changes in pre- and postjunctional alpha-adrenoceptors in human saphenous vein", European Journal of Pharmacology, vol. 114, no. 3, pp. 361-36410.1016/0014-2999(85)90381-4.

Jain, A., Brönneke, S., Kolbe, L., Stäb, F., Wenck, H. \& Neufang, G. 2011, "TRP-channelspecific cutaneous eicosanoid release patterns", Pain, vol. 152, no. 12, pp. 2765277210.1016/j.pain.2011.08.025.

Johnson, J.M., Yen, T.C., Zhao, K. \& Kosiba, W.A. 2005, "Sympathetic, sensory, and nonneuronal contributions to the cutaneous vasoconstrictor response to local cooling", American Journal of Physiology-Heart and Circulatory Physiology, vol. 288, no. 4, pp. H1573-H157910.1152/ajpheart.00849.2004.

Karashima, Y., Talavera, K., Everaerts, W., Janssens, A., Kwan, K.Y., Vennekens, R., Nilius, B. \& Voets, T. 2009, "TRPA1 acts as a cold sensor in vitro and in vivo", Proceedings of the National Academy of Sciences of the United States of America, vol. 106, no. 4, pp. 1273-127810.1073/pnas.0808487106.

Keatinge, W.R. 1957, "The effect of general chilling on the vasodilator response to cold", The Journal of Physiology, vol. 139, no. 3, pp. 497-50710.1113/jphysiol.1957.sp005908.

Kobayashi, K., Fukuoka, T., Obata, K., Yamanaka, H., Dai, Y., Tokunaga, A. \& Noguchi, K. 2005, "Distinct expression of TRPM8, TRPA1, and TRPV1 mRNAs in rat primary afferent neurons with aס/c-fibers and colocalization with trk receptors", Journal of Comparative Neurology, vol. 493, no. 4, pp. 596-60610.1002/cne.20794.

Kwan, K.Y., Allchorne, A.J., Vollrath, M.A., Christensen, A.P., Zhang, D., Woolf, C.J. \& Corey, D.P. 2006, "TRPA1 Contributes to Cold, Mechanical, and Chemical Nociception but Is Not Essential for Hair-Cell Transduction", Neuron, vol. 50, no. 2, pp. 27728910.1016/j.neuron.2006.03.042.

Lewis, T. 1930, "Observations upon the reactions of the vessels of the human skin to cold", Heart, vol. 15, pp. 177-208.

Luiz, A.P., MacDonald, D.I., Santana-Varela, S., Millet, Q., Sikandar, S., Wood, J.N. \& Emery, E.C. 2019, "Cold sensing by NaV1.8-positive and NaV1.8-negative sensory neurons", Proceedings of the National Academy of Sciences of the United States of America, vol. 116, no. 9, pp. 3811-381610.1073/pnas.1814545116.

McKemy, D.D., Neuhausser, W.M. \& Julius, D. 2002, "Identification of a cold receptor reveals a general role for TRP channels in thermosensation", Nature, vol. 416, no. 6876, pp. 52-5810.1038/nature719.

Moraes, M.N., de Assis, Leonardo Vinicius Monteiro, Henriques, F.D.S., Batista, M.L., Güler, A.D. \& Castrucci, Ana Maria de Lauro 2017, "Cold-sensing TRPM8 channel participates in circadian control of the brown adipose tissue", Biochimica Et Biophysica Acta. Molecular Cell Research, vol. 1864, no. 12, pp. 2415242710.1016/j.bbamcr.2017.09.011.

Morrison, S.F. \& Nakamura, K. 2019, "Central Mechanisms for Thermoregulation", Annual Review of Physiology, vol. 81, pp. 285-30810.1146/annurev-physiol-020518-114546. 
Morrison, S.F. \& Nakamura, K. 2011, "Central neural pathways for thermoregulation", Frontiers in Bioscience (Landmark Edition), vol. 16, pp. 74-10410.2741/3677.

Mühlberg, W. \& Platt, D. 1999, "Age-dependent changes of the kidneys: pharmacological implications", Gerontology, vol. 45, no. 5, pp. 243-25310.1159/000022097.

Nassini, R., Materazzi, S., Benemei, S. \& Geppetti, P. 2014, "The TRPA1 channel in inflammatory and neuropathic pain and migraine", Reviews of Physiology, Biochemistry and Pharmacology, vol. 167, pp. 1-4310.1007/112_2014_18.

Noël, J., Zimmermann, K., Busserolles, J., Deval, E., Alloui, A., Diochot, S., Guy, N., Borsotto, M., Reeh, P., Eschalier, A. \& Lazdunski, M. 2009, "The mechano-activated K+ channels TRAAK and TREK- 1 control both warm and cold perception", The EMBO Journal, vol. 28, no. 9, pp. 1308-131810.1038/emboj.2009.57.

Office for National Statistics 2019, "Excess winter mortality in England and Wales: 2018 to 2019 (provisional) and 2017 to 2018 (final)", Office for National Statistics, .

Pal, R., Singh, S.N., Chatterjee, A. \& Saha, M. 2014, "Age-related changes in cardiovascular system, autonomic functions, and levels of BDNF of healthy active males: role of yogic practice", Age (Dordrecht, Netherlands), vol. 36, no. 4, pp. 968310.1007/s11357-0149683-7.

Pan, Y., Thapa, D., Baldissera, L., Argunhan, F., Aubdool, A.A. \& Brain, S.D. 2018, "Relevance of TRPA1 and TRPM8 channels as vascular sensors of cold in the cutaneous microvasculature", Pflugers Archiv, vol. 470, no. 5, pp. 77978610.1007/s00424-017-2085-9.

Peier, A.M., Moqrich, A., Hergarden, A.C., Reeve, A.J., Andersson, D.A., Story, G.M., Earley, T.J., Dragoni, I., McIntyre, P., Bevan, S. \& Patapoutian, A. 2002, "A TRP Channel that Senses Cold Stimuli and Menthol", Cell, vol. 108, no. 5, pp. 70571510.1016/S0092-8674(02)00652-9.

Peixoto-Neves, D., Soni, H. \& Adebiyi, A. 2018, "Oxidant-induced increase in norepinephrine secretion from PC12 cells is dependent on TRPM8 channel-mediated intracellular calcium elevation", Biochemical and Biophysical Research Communications, vol. 506, no. 3, pp. 709-71510.1016/j.bbrc.2018.10.120.

Peters, R. 2006, "Ageing and the brain", Postgraduate Medical Journal, vol. 82, no. 964, pp. 84-8810.1136/pgmj.2005.036665.

Reimúndez, A., Fernández-Peña, C., García, G., Fernández, R., Ordás, P., Gallego, R., Pardo-Vazquez, J.L., Arce, V., Viana, F. \& Señarís, R. 2018, "Deletion of the Cold Thermoreceptor TRPM8 Increases Heat Loss and Food Intake Leading to Reduced Body Temperature and Obesity in Mice", Journal of Neuroscience, vol. 38, no. 15, pp. 3643-3656.

Roustit, M., Blaise, S., Millet, C. \& Cracowski, J. 2011, "Impaired transient vasodilation and increased vasoconstriction to digital local cooling in primary Raynaud's phenomenon", American Journal of Physiology. Heart and Circulatory Physiology, vol. 301, no. 2, pp. 32410.1152/ajpheart.00246.2011.

Señarís, R., Ordás, P., Reimúndez, A. \& Viana, F. 2018, "Mammalian cold TRP channels: impact on thermoregulation and energy homeostasis", Pflugers Archiv: European Journal of Physiology, vol. 470, no. 5, pp. 761-77710.1007/s00424-018-2145-9. 
997

998

999

1000

1001

1002

1003

1004

1005

1006

1007

1008

1009

1010

1011

1012

1013

1014

1015

1016

1017

1018

1019

1020

1021

1022

1023

1024

1025

1026

1027

1028

1029

1030

1031

1032

1033

1034

1035

Sharpless, N.E. \& Sherr, C.J. 2015, "Forging a signature of in vivo senescence", Nature Reviews. Cancer, vol. 15, no. 7, pp. 397-40810.1038/nrc3960.

Sharrad, D.F., Hibberd, T.J., Kyloh, M.A., Brookes, S.J.H. \& Spencer, N.J. 2015, "Quantitative immunohistochemical co-localization of TRPV1 and CGRP in varicose axons of the murine oesophagus, stomach and colorectum", Neuroscience Letters, vol. 599, pp. 164-17110.1016/j.neulet.2015.05.020.

Silva, D.F., Wenceslau, C.F., Mccarthy, C.G., Szasz, T., Ogbi, S. \& Webb, R.C. 2019, "TRPM8 channel activation triggers relaxation of pudendal artery with increased sensitivity in the hypertensive rats", Pharmacological research, vol. 147, pp. 10432910.1016/j.phrs.2019.104329.

Smith, M.P., Beacham, D., Ensor, E. \& Koltzenburg, M. 2004, "Cold-sensitive, mentholinsensitive neurons in the murine sympathetic nervous system", Neuroreport, vol. 15, no. 9, pp. 1399-140310.1097/01.wnr.0000126559.35631.54.

Stares, J. \& Kosatsky, T. 2015, "Hypothermia as a cause of death in British Columbia, 1998-2012: a descriptive assessment", CMAJ Open, vol. 3, no. 4, pp. E352E35810.9778/cmajo.20150013.

Story, G.M., Peier, A.M., Reeve, A.J., Eid, S.R., Mosbacher, J., Hricik, T.R., Earley, T.J., Hergarden, A.C., Andersson, D.A., Hwang, S.W., Mclntyre, P., Jegla, T., Bevan, S. \& Patapoutian, A. 2003, "ANKTM1, a TRP-like channel expressed in nociceptive neurons, is activated by cold temperatures", Cell, vol. 112, no. 6, pp. 819-829.

Terenghi, G., Zhang, S.Q., Unger, W.G. \& Polak, J.M. 1986, "Morphological changes of sensory CGRP-immunoreactive and sympathetic nerves in peripheral tissues following chronic denervation", Histochemistry, vol. 86, no. 1, pp. 89-9510.1007/BF00492350.

Thompson, C.S., Holowatz, L.A. \& Kenney, W.L. 2005, "Attenuated noradrenergic sensitivity during local cooling in aged human skin", The Journal of Physiology, vol. 564, no. Pt 1, pp. 313-31910.1113/jphysiol.2004.080788.

Yang, X., Lin, M., McIntosh, L.S. \& Sham, J.S.K. 2006, "Functional expression of transient receptor potential melastatin- and vanilloid-related channels in pulmonary arterial and aortic smooth muscle", American Journal of Physiology. Lung Cellular and Molecular Physiology, vol. 290, no. 6, pp. 126710.1152/ajplung.00515.2005.

Yoshimura, R., Nakagawa, M. \& Endo, Y. 2016, "Cold stimulation evokes exocytotic vesicle release from PC12 cells", Biomedical Research (Tokyo, Japan), vol. 37, no. 6, pp. 38138310.2220/biomedres.37.381.

Zimmermann, K., Lennerz, J.K., Hein, A., Link, A.S., Kaczmarek, J.S., Delling, M., Uysal, S., Pfeifer, J.D., Riccio, A. \& Clapham, D.E. 2011, "Transient receptor potential cation channel, subfamily $\mathrm{C}$, member 5 (TRPC5) is a cold-transducer in the peripheral nervous system", Proceedings of the National Academy of Sciences of the United States of America, vol. 108, no. 44, pp. 18114-1811910.1073/pnas.1115387108. 
Supplementary Figure 1: Analysis of cold-induced blood flow in the mouse paw (a) The blood flow graph from cold treatment was used to calculate the maximum vasoconstriction, area under the curve (AUC) analysis of vasoconstriction and recovery of blood flow from cold treatment. It was not possible to measure blood flow whilst the paw was being cooled. The highlighted areas in blue shows the area of the graph from start of the 5 min baseline (BL) until peak vasoconstriction that was used to calculate the AUC analysis to detail the magnitude of the vasoconstrictor event. The time of immediate blood flow recovery $(T)$ was calculated by measuring the time immediately after maximum vasoconstriction until it started to plateau back to baseline level (as shown by blue lines). ( $\mathrm{BL}=$ Baseline). The maximum change of blood flow (\%) was calculated using the equation below:

1065

Max change of blood flow $(\%)=\frac{\text { Max vasoconstriction }- \text { baseline }}{\times 100 \%}$

baseline 
a

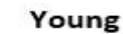
Aged Young Aged

1075

1076

1077

1078

1079

1080

1081

1082

1083

1084

1085

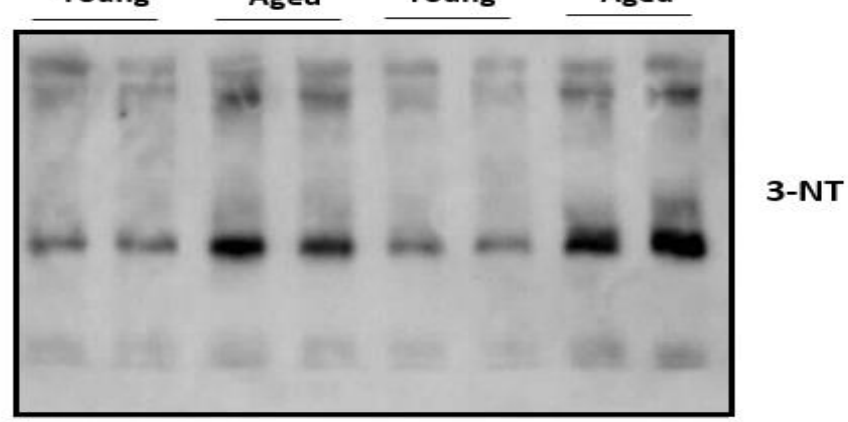

1086

1088

1089

Supplementary Figure 2: Oxidative stress with ageing. (a) The representative western blot 1090

1091

1092

1093

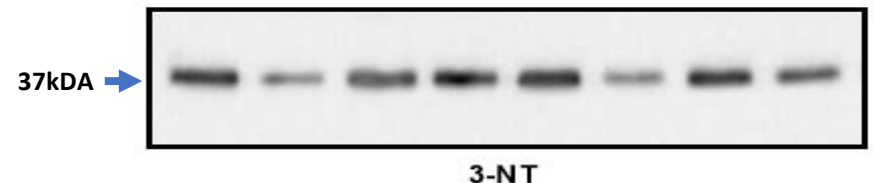

GAPDH

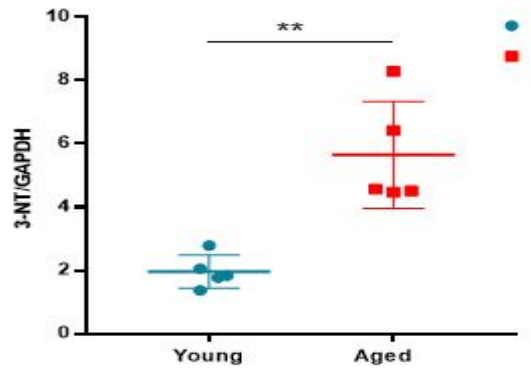
analysis of 3-nitrotyrosine (3-NT), which is a biomarker of oxidative stress produced by reactive nitrogen species, in hind paw skin of naïve young and aged mice. The densitometric analysis is shown normalized to GAPDH housekeeping gene. Results are shown as mean \pm s.e.m. $(n=5){ }^{* *} p<0.01$. (Two-tailed Student's t-test).

1094

1095

1096

1097

1098

1099

1100

1101

1102 
a

1109

1110

1111

1112

1113

1114

1115

1116

1117

1118

1119

1120

1121

1122

1123

1124

1125

1126

1127

1128

1129

1130

1131

1132

1133 b

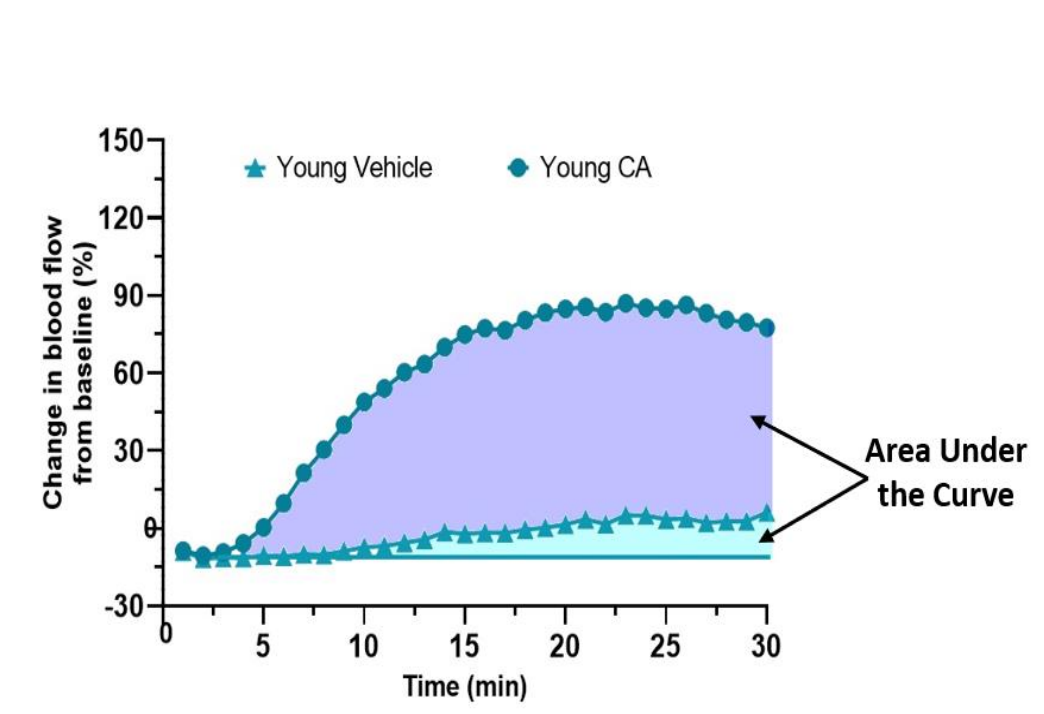

Supplementary Figure 3: Agonist induced blood flow response in mouse ear. (a) The representative image from FLPI shows the blood flow response induced by topical application of vehicle (left ear) and 10\% cinnamaldehyde (right ear) in the anaesthetised mouse. (b) The representative blood flow response graph illustrates the area used for the area under the curve analysis for vehicle (light blue) and cinnamaldehyde (purple).

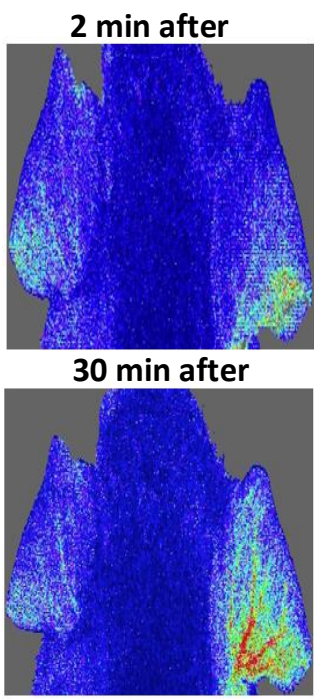


a

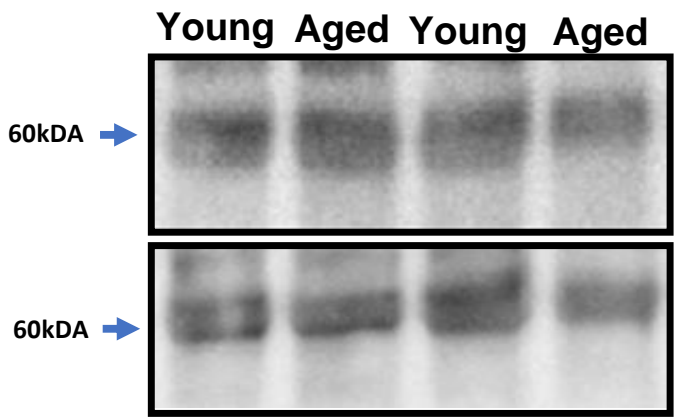

Phospho- tyrosine hydroxylase

Tyrosine hydroxylase

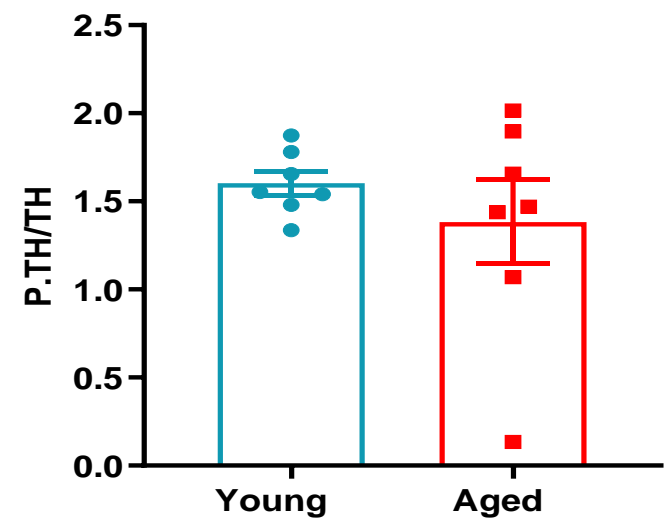

1151

1152

Supplementary Figure 4: Phospho-tyrosine hydroxylase with ageing. (a) The 1153 representative western blot analysis of phospho-tyrosine hydroxylase in hind paw skin of naïve 1154 young and aged mice. The densitometric analysis is normalized to total tyrosine hydroxylase. Results are shown as mean \pm s.e.m. $(n=7)$ (Two-tailed Student's t-test). 
a

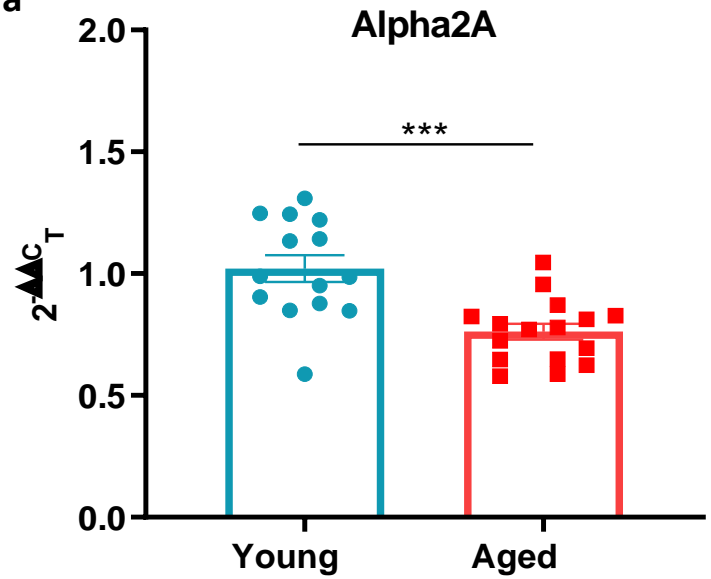

b

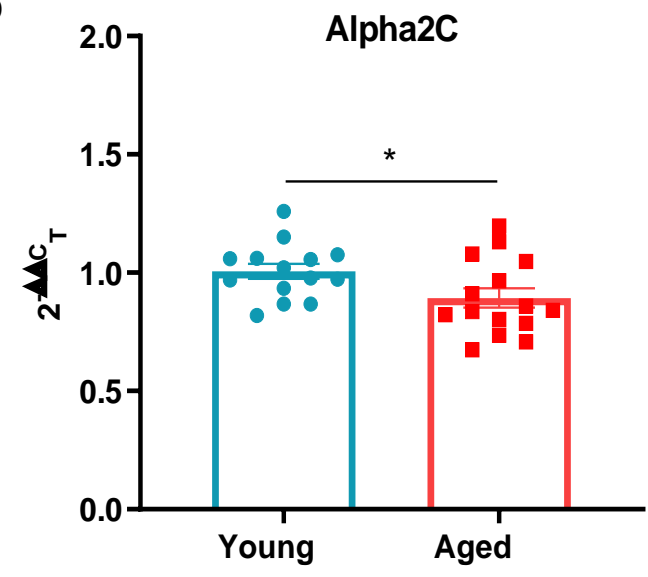

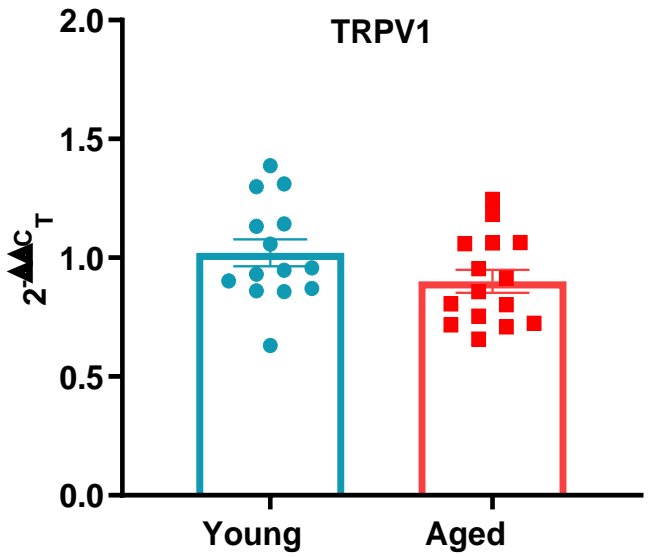
RT-PCR CT analysis shows fold change of $\alpha_{2 a}$ adrenoceptor, $\alpha_{2 c}$ adrenoceptor and TRPV1 in young and aged mice normalized to three housekeeping genes in dorsal root ganglia (DRG). Results are shown as mean \pm s.e.m. $(n=14-16){ }^{*} p<0.05,{ }^{* * *} p<0.001$. (Two-tailed Student's $t-$ test). 
a

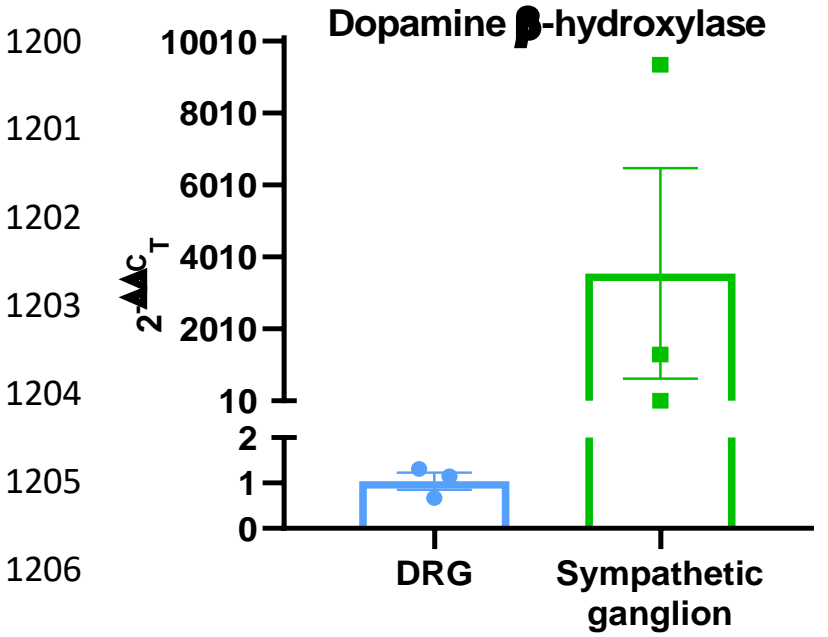

b

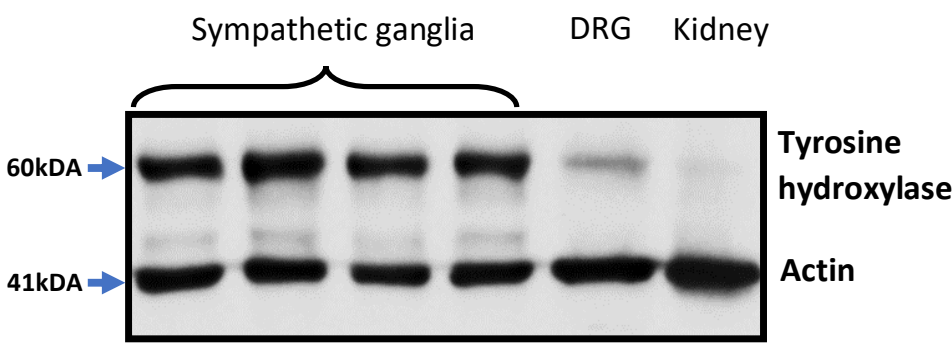

1207

1208

1209

1210

1211

1212

1213

1214

1215

1216

1217

1218

1219

1220

1221

1222

1223

1224

1225

Supplementary figure 6. Characterisation of sympathetic markers (a) RT-PCR CT analysis shows fold change of the sympathetic nerve marker dopamine $\beta$-hydroxylase (Dbh) in DRG and sympathetic ganglia normalized to three housekeeping genes. (b) The western blot analysis of the sympathetic nerve marker tyrosine hydroxylase (TH) in sympathetic ganglia, DRG and kidney. Results are shown as mean \pm s.e.m. $(n=3)$. 
1228 Supplementary Table 1. List of primer sequences

1229

\begin{tabular}{|c|c|c|c|c|}
\hline $\begin{array}{l}\text { Gene } \\
\text { Name }\end{array}$ & RefSeq ID & Forward Sequence & Reverse Sequence & $\begin{array}{l}\text { Amplicon } \\
\text { Size (bp) }\end{array}$ \\
\hline TRPA1 & NM_001348288.1 & GAGGATTGCTATGCAGGTGGA & TCCACTTTGCGCAAGTACCA & 75 \\
\hline TRPV1 & NM_001001445.2 & CAACAAGAAGGGGCTTACACC & TCTGGAGAATGTAGGCCAAGAC & 77 \\
\hline TRPM8 & NM_134252.4 & TTGTATTCCGGCTCCACTCTTC & AGTTCCTGCTGACGGTGAAAA & 120 \\
\hline$\alpha_{2 A}$ & NM_007417.5 & TCATCTCCTCGTCCATCGGT & ACGCTTGGCGATCTGGTAAA & 86 \\
\hline$\alpha_{2 c}$ & NM_007418.3 & ACAAGCGCACTCTCCAATCA & AGTCTCCACCTCACTCGGTT & 106 \\
\hline p16 & NM_001040654.1 & CCATCTGGAGCAGCATGGAGT & TCATCATCACCTGAATCGGGGTA & 150 \\
\hline p21 & NM_001111099.2 & CAGCAGAATAAAAGGTGCCACA & CACGGGACCGAAGAGACAAC & 100 \\
\hline GAPDH & NM_001289726.1 & GGTCATCCCAGAGCTGAACG & TTGCTGTTGAAGTCGCAGGA & 294 \\
\hline B2M & NM_009735.3 & GCCTGTATGCTATCCAGAAAACCCC & TGTGAGGCGGGTGGAACTGTG & 114 \\
\hline Act & NM_007393.5 & CACTGTCGAGTCGCGTCCA & GTCATCCATGGCGAACTGGTG & 90 \\
\hline HPRT & NM_013556.2 & TCCTCCTCAGACCGCTTTT & CCTGGTTCATCATCGCTAATC & 90 \\
\hline Dbh & NM_138942.3 & TACTTTGCGGATGCCTGGAG & ATCTCGAGTCCTCTGTGCCT & 93 \\
\hline TH & NM_009377.2 & AGGGCCTCTATGCTACCCAT & AAGCCAGTCCGTTCCTTCAA & 136 \\
\hline
\end{tabular}

Act- beta actin

HPRT- hypoxanthine guanine phosphoribosyl transferase

B2M - $\beta 2$ microglobulin

GAPDH - Glyceraldehyde 3-phosphate dehydrogenase

Dbh - dopamine $\beta$-hydroxylase

TH - tyrosine hydroxylase

$\alpha_{2 a}$ - alpha2a adrenoceptor

$\alpha_{2 c}$ - alpha2c adrenoceptor 